Article

\title{
Fault-Tolerant Neuro Adaptive Constrained Control of Wind Turbines for Power Regulation with Uncertain Wind Speed Variation
}

\author{
Hamed Habibi ${ }^{1}$ (D) Hamed Rahimi Nohooji ${ }^{2}$ (D) Ian Howard ${ }^{1}$ and Silvio Simani $^{3, *(D)}$ \\ 1 Faculty of Science and Engineering, School of Civil and Mechanical Engineering, Curtin University, \\ Perth 6102, Australia; hamed.habibi@postgrad.curtin.edu.au (H.H.); i.howard@curtin.edu.au (I.H.) \\ 2 Center for Research in Mechatronics, Institute of Mechanics, Materials, and Civil Engineering, \\ Université Catholique de Louvain, 1348 Louvain-la-Neuve, Belgium; hamed.rahimi@uclouvain.be \\ 3 Department of Engineering, University of Ferrara, 44100 Ferrara, Italy \\ * Correspondence: silvio.simani@unife.it
}

Received: 20 October 2019; Accepted: 9 December 2019; Published: 10 December 2019

\begin{abstract}
This paper presents a novel adaptive fault-tolerant neural-based control design for wind turbines with an unknown dynamic and unknown wind speed. By utilizing the barrier Lyapunov function in the analysis of the Lyapunov direct method, the constrained behavior of the system is provided in which the rotor speed, its variation, and generated power remain in the desired bounds. In addition, input saturation is also considered in terms of smooth pitch actuator bounding. Furthermore, by utilizing a Nussbaum-type function in designing the control algorithm, the unpredictable wind speed variation is captured without requiring accurate wind speed measurement, observation, or estimation. Moreover, with the proposed adaptive analytic algorithms, together with the use of radial basis function neural networks, a robust, adaptive, and fault-tolerant control scheme is developed without the need for precise information about the wind turbine model nor the pitch actuator faults. Additionally, the computational cost of the resultant control law is reduced by utilizing a dynamic surface control technique. The effectiveness of the developed design is verified using theoretical analysis tools and illustrated by numerical simulations on a high-fidelity wind turbine benchmark model with different fault scenarios. Comparison of the achieved results to the ones that can be obtained via an available industrial controller shows the advantages of the proposed scheme.
\end{abstract}

Keywords: adaptive constrained control; barrier Lyapunov function; fault-tolerant control; Nussbaum-type function; pitch actuator; power regulation; robustness evaluation

\section{Introduction}

The key factor for the enhancement of the efficiency of a wind turbine is how to develop the control structure. Specifically, the pitch control design is a vital step in variable pitch wind turbines working in high wind speed, i.e., so-called full load region, to avoid hazardous operation as well as to avoid conservative power generation, i.e., less than nominal power [1]. This objective is often known as power regulation for nominal power generation [2]. Accordingly, the control design of wind turbines in power regulation has gained significant importance during the last decades [3]. Several industrial controllers for power regulation use the Proportional-Integral-Derivative (PID) type control, as the linear controller $[4,5]$. However, as wind turbines are complex nonlinear dynamic processes, linear controllers may not accurately render the expected performance [6]. Consequently, in the last decade, modern and advanced controller schemes have been adopted to regulate power generation accurately, e.g., linear parameter varying control [7], gain scheduling [8], adaptive nonlinear control [9], optimal 
control [10], evolutionary algorithms [11], robust control [12], and fuzzy logic systems [13]. A detailed review of power regulation controllers designed for wind turbines can be found in [14].

Wind turbine operation in the presence of high wind speed variation may lead to pitch actuator faults, which in turn leads to poor power regulation and catastrophic operation $[4,15]$. These faults can be considered as pitch actuator bias, effectiveness loss, and dynamic change [2]. Also, the debris build-up and blade erosion change the aerodynamic characteristics of the blades [16]. The presence of faults can increase the need for maintenance operations and downtimes, which may lead to a decrease of the power generation and increase of the cost, particularly for offshore wind farms, installed in remote places that are sometimes difficult to reach $[17,18]$. Thus, it is desirable to integrate the fault tolerance capability into the pitch actuator controller to attenuate the fault effects and keep the performance at the desired level, especially for large rotor and offshore deployments [7]. Therefore, in the development of the wind turbine control structure, the fault-tolerant pitch controller design has been considered, and different approaches have been proposed, such as fuzzy control [19], adaptive sliding mode control [4], and robust linear parameter varying control [16].

In reality, the wind turbine's aerodynamic torque is a nonlinear function of wind speed [20]. On the other hand, the pitch angle variation adjusts the speed via regulating the aerodynamic torque. However, the wind speed is a highly stochastic variable. Accordingly, it can be stated that the control function, from the pitch angle to the aerodynamic torque, is not completely known. This leads to the unknown control direction problem. Therefore, considering uncertain wind speed variation in the pitch angle control design of wind turbines is a significant challenge [21]. In [22], a nonstandard extended Kalman filter is developed to estimate the wind speed for maximum power extraction of variable speed wind turbines. In [23], a comparative study using soft computing methodologies for the estimation of wind speed was presented. A review of the effective wind speed estimation-based control of wind turbines can be found in [24]. Even though numerous methodologies have addressed wind speed estimation of wind turbines, the presented structures are still found to be very complicated and ineffective in practice.

On the other hand, in the full load region, if the wind turbine speed increases and violates the predefined limits, the mechanical brakes, located on the rotor, are engaged [15]. This leads to generated power reduction considerably lower than the nominal one. Also, excessive rotor speeds in wind turbine operation may lead to a hazardous situation. Thus, to ensure safe operation of wind turbines, the rotor speed and its variation must be constrained within the safe-to-operate bounds. By that means, the variation of the generated power around the nominal power can be constrained at some predefined bounds. These bounds are designed within which the engagement of the mechanical brake is avoided. However, there are very limited works available in the literature that consider the constrained power generation. To fill this gap in the past literature, the authors recently developed a new strategy for constrained power generation [5], which can be viewed as an extension of the direct Lyapunov method to constrained systems. The core of this method consists of developing a barrier Lyapunov function (BLF) to constrain the generator speed and the generated power. An essential advantage of the BLF is that it guarantees that the corresponding arguments are constrained [25]. The algorithm proposed by the authors in [5] uses the logarithm-type BLF for nonlinear wind turbines to constrain the generator speed and thus to generate the constrained power. However, in the authors' study, constrained performance was not guaranteed in the presence of faults. Also, the uncertain wind speed variation was not considered in designing the previous constrained control scheme.

Motivated by the aforementioned considerations, the primary objective of this paper was to design the pitch actuator control of wind turbines under uncertain wind speed variation to constrain the rotor speed and the generated power within the safe-to-operate bounds. These bounds were defined in order to avoid the engagement of the mechanical brake. In this manner, the overspeeding as well as the conservative power generation problems are resolved. The main idea consists of developing the BLF-based control to provide constrained behavior and further utilizing a Nussbaum-type function to cope with the unknown wind speed variation. The former is utilized to keep the generated 
power within the given desirable constraints, provided by the designer, and the latter is exploited to regulate the power without requiring accurate wind speed measurement, observation, or estimation. The controller is further developed to tolerate the pitch actuator faults for nonlinear wind turbine models. This considerably increases the reliability and efficiency as well. Thanks to the dynamic surface control (DSC) technique, the computational complexity of the control scheme is reduced by avoiding the repetitive differentiation of virtual control in the controller structure. In addition, the pitch actuator effort is smoothly bounded to avoid pitch actuator saturation. The second objective of the paper was to design a fault identification scheme to investigate the estimated fault signal, and then accurately generate fault information, which consists of fault detection, isolation, and type/size estimation. The fault identification task may be employed, for example, for planning effective and timely maintenance of offshore deployments, thus reducing the downtime of plants and the cost. Also, the availability is enhanced. In addition, to estimate the uncertain aerodynamic torque, a radial basis function (RBF) neural network is used, whose weights are automatically tuned without requiring any early training scheme. Finally, the numerical simulation is conducted to evaluate the proposed controller performance. Also, a comparison between the proposed controller and the available industrial PID controller is made considering the numerical control criteria, which are used to quantify the performance of both controllers. Accordingly, the contribution of this paper can be summarized as follows.

1. With the adoption of BLF-based constrained control, the rotor speed and its variation are constrained, and consequently, the variation of generated power around the nominal power will not violate the predefined constraint. This guarantees safe desirable nominal power generation, and less mechanical brake engagement.

2. The Nussbaum-type function is adopted to handle the unknown control direction problem, which stems from an uncertain wind speed and consequent uncertain aerodynamic torque variation. Accordingly, the need for accurate wind speed measurement is avoided.

3. The pitch actuator fault effects, including effectiveness loss, pitch angle bias, hydraulic leak, high air content in the oil, and pump wear, are compensated for automatically via an adaptive fault-tolerant controller design. Also, the effect of blade aerodynamic characteristic changes, due to debris build-up and erosion, is considered and mitigated. The fault information, including fault type, size, and time, is estimated, which can be used for maintenance operations.

4. Smooth pitch actuator saturation is designed to avoid the harsh and fast pitch actuator saturation phenomenon, which may increase the structural load on the wind turbine and result in performance degradation. Also, a neural network estimator is adaptively augmented in the proposed controller to obtain the uncertain aerodynamic torque.

5. The control design is fulfilled in the backstepping framework, utilizing the virtual control concept. In this regard, the repeated differentiation of virtual control is required, which increases the complexity of the designed controller order. The DSC technique is used to eliminate this problem by introducing a first-order filter [25].

The rest of this paper is organized as follows. In Section 2, the wind turbine model is summarized. In Section 3, pitch actuator saturation and faults are introduced. In Section 4, the desired operational mode and objectives are introduced. Accordingly, the proposed controller is designed in Section 5, and the fault identification scheme is described in Section 6. The numerical evaluation of the proposed controller is addressed in Section 7 and the results are discussed. Finally, concluding remarks and open problems are given in Section 8. 


\section{Nominal Wind Turbine Model}

The wind kinetic energy is captured by the blades and transferred into the rotor, rotating at $\omega_{\mathrm{r}}$. The effective wind speed, $V_{r}$, causes an induced aerodynamic torque, $T_{a}$, and thrust, $F_{t}$, modelled as [2]:

$$
\mathrm{T}_{\mathrm{a}}=\frac{1}{2} \rho_{\mathrm{a}} \pi \mathrm{R}^{3} \mathrm{~V}_{\mathrm{r}}^{2} \mathrm{C}_{\mathrm{q}}(\beta, \lambda), \mathrm{F}_{\mathrm{t}}=\frac{1}{2} \rho_{\mathrm{a}} \pi \mathrm{R}^{2} \mathrm{~V}_{\mathrm{r}}^{2} \mathrm{C}_{\mathrm{t}}(\beta, \lambda),
$$

where $\rho_{\mathrm{a}}$ is the air density and $\mathrm{R}$ is the blade length. Also, $\mathrm{C}_{\mathrm{q}}$ and $\mathrm{C}_{\mathrm{t}}$ are the torque and thrust coefficients. These coefficients are functions of the blade pitch angle, $\beta$, and tip speed ratio, $\lambda$, defined as $\lambda=R \omega_{r} / V_{r}$ [2]. Considering the long elastic tower, $T_{a}$ causes a fore-aft oscillation of the nacelle, i.e., a bending oscillation of the tower. This motion is modelled as [7]:

$$
\mathrm{M}_{\mathrm{t}} \ddot{\mathrm{x}}_{\mathrm{t}}=\mathrm{F}_{\mathrm{t}}-\mathrm{B}_{\mathrm{t}} \dot{\mathrm{x}}_{\mathrm{t}}-\mathrm{K}_{\mathrm{t}} \mathrm{x}_{\mathrm{t}}
$$

where $B_{t}, K_{t}$, and $M_{t}$ represent the damping ratio, and the elasticity coefficient of the tower and nacelle mass, respectively. Also, the nacelle displacement from its equilibrium position is represented by $x_{t}$. The effective wind speed at the rotor plane is then obtained as $V_{r}=V_{w}-\dot{x}_{t}$, where $V_{w}$ is the free wind speed, which itself is the wind speed before encountering the blades [9]. The captured aerodynamic power by the wind turbine is then written as:

$$
\mathrm{P}_{\mathrm{a}}=\frac{1}{2} \rho_{\mathrm{a}} \pi \mathrm{R}^{2} \mathrm{~V}_{\mathrm{r}}^{3} \mathrm{C}_{\mathrm{p}}(\beta, \lambda),
$$

where, $C_{p}$ represents the power coefficient. Also, considering $P_{a}=T_{a} \omega_{r}$, the relation between the power and torque coefficients is $C_{p}=C_{q} \lambda$. The empirical equation of $C_{p}$ is stated as [26]:

$$
\mathrm{C}_{\mathrm{p}}(\beta, \lambda)=\mathrm{C}_{1}\left(\mathrm{C}_{2} / \lambda_{\mathrm{i}}-\mathrm{C}_{3} \beta-\mathrm{C}_{4}\right) \mathrm{e}^{\left(-\mathrm{C}_{5} / \lambda_{\mathrm{i}}\right)}+\mathrm{C}_{6} \lambda,
$$

where $1 / \lambda_{i}=1 /(\lambda+0.08 \beta)-0.035 /\left(\beta^{3}+1\right), C_{1}=0.5176, C_{2}=116, C_{3}=0.4, C_{4}=5, C_{5}=21$, and $\mathrm{C}_{6}=0.0068$. Also, $\mathrm{C}_{\mathrm{t}}$ can be approximated as [27]:

$$
\begin{gathered}
\mathrm{C}_{\mathrm{T}}(\beta, \lambda)=0.5 \widetilde{\mathrm{C}}_{\mathrm{T}}\left(1+\operatorname{sign}\left(\widetilde{\mathrm{C}}_{\mathrm{T}}\right)\right), \\
\widetilde{\mathrm{C}}_{\mathrm{T}}=\mathrm{A}_{1}+\mathrm{A}_{2}\left(\lambda-\mathrm{A}_{3} \beta\right) \mathrm{e}^{-\mathrm{A}_{4} \beta}+\mathrm{A}_{5} \lambda^{2} \mathrm{e}^{-\mathrm{A}_{6} \beta}+\mathrm{A}_{7} \lambda^{3} \mathrm{e}^{-\mathrm{A}_{8} \beta},
\end{gathered}
$$

where $\mathrm{A}_{1}=0.006, \mathrm{~A}_{2}=0.095, \mathrm{~A}_{3}=-4.15, \mathrm{~A}_{4}=2.75, \mathrm{~A}_{5}=0.001, \mathrm{~A}_{6}=7.8, \mathrm{~A}_{7}=-0.00016$, and $\mathrm{A}_{8}=-8.88$. The drive train is used to increase the rotor speed, $\omega_{\mathrm{r}}$, and transfer the kinetic energy into the generator shaft, rotating at $\omega_{\mathrm{g}}$. The drive train is modelled as a two-mass system. The rotor and generator shafts have an inertia of $\mathrm{J}_{\mathrm{r}}$ and $\mathrm{J}_{\mathrm{g}}$, respectively. The elastic gear meshing is considered, with the inclusion of the torsion stiffness, $\mathrm{K}_{\mathrm{dt}}$, and the torsion damping, $\mathrm{B}_{\mathrm{dt}}$. This elastic gear meshing leads to a torsional angle of twist, $\theta_{\Delta}$, defined as:

$$
\theta_{\Delta}=\theta_{\mathrm{r}}-\frac{\theta_{\mathrm{g}}}{\mathrm{N}_{\mathrm{g}}}
$$

where $\theta_{\mathrm{r}}$ and $\theta_{\mathrm{g}}$ are the rotation angle of the rotor and generator shafts, respectively. Also, the viscous friction at the bearings of the rotor and generator shafts are modelled with coefficients $B_{r}$ and $B_{g}$, respectively. The drive train efficiency is $\eta_{\mathrm{dt}}$. So, the drive train is modelled as [15]:

$$
\begin{gathered}
\mathrm{J}_{\mathrm{r}} \dot{\omega}_{\mathrm{r}}=\mathrm{T}_{\mathrm{a}}-\mathrm{K}_{\mathrm{dt}} \theta_{\Delta}-\left(\mathrm{B}_{\mathrm{r}}+\mathrm{B}_{\mathrm{dt}}\right) \omega_{\mathrm{r}}+\frac{\mathrm{B}_{\mathrm{dt}}}{\mathrm{N}_{\mathrm{g}}} \omega_{\mathrm{g}}, \\
\mathrm{J}_{\mathrm{g}} \dot{\omega}_{\mathrm{g}}=\frac{\eta_{\mathrm{dt}} \mathrm{K}_{\mathrm{dt}}}{\mathrm{N}_{\mathrm{g}}} \theta_{\Delta}+\frac{\eta_{\mathrm{dt}} \mathrm{B}_{\mathrm{dt}}}{N_{\mathrm{g}}} \omega_{\mathrm{r}}-\left(\mathrm{B}_{\mathrm{g}}+\frac{\eta_{\mathrm{dt}} \mathrm{B}_{\mathrm{dt}}}{\mathrm{N}_{\mathrm{g}}{ }^{2}}\right) \omega_{\mathrm{g}}-\mathrm{T}_{\mathrm{g}}, \\
\dot{\theta}_{\Delta}=\omega_{\mathrm{r}}-\frac{1}{\mathrm{~N}_{\mathrm{g}}} \omega_{\mathrm{g}} .
\end{gathered}
$$


The generator speed, rotor speed, and their time derivative sensors are modelled as, $\omega_{\mathrm{g}, \mathrm{s}}=$ $\omega_{\mathrm{g}}+v_{\omega_{\mathrm{g}}}, \omega_{\mathrm{r}, \mathrm{s}}=\omega_{\mathrm{r}}+v_{\omega_{\mathrm{r}}}$, and $\dot{\omega}_{\mathrm{r}, \mathrm{s}}=\dot{\omega}_{\mathrm{r}}+v_{\dot{\omega}_{\mathrm{r}}}$, where $v_{\omega_{\mathrm{g}}}, v_{\omega_{\mathrm{r}}}$, and $v_{\dot{\omega}_{\mathrm{r}}}$ are noise contents [2].

The generator shaft kinetic energy is converted into electrical energy in the generator. Also, a converter is located between the generator and the electrical grid to adjust the generated power frequency [7]. The generator internal electronic controller is much faster than the mechanical dynamic behavior of wind turbines. So, it is assumed that the generator torque, $\mathrm{T}_{\mathrm{g}}$, is adjusted at the generator reference torque fast enough to ignore the generator dynamic response. Also, the generated electrical power, $\mathrm{P}_{\mathrm{g}}$, is approximated as a static function given by [7]:

$$
\mathrm{P}_{\mathrm{g}}=\eta_{\mathrm{g}} \omega_{\mathrm{g}} \mathrm{T}_{\mathrm{g}}
$$

where $\eta_{\mathrm{g}}$ is the generator efficiency.

The hydraulic pitch actuator rotates the blades to regulate $\beta$ at the desired one, $\beta_{\mathrm{u}}$, tuned by the pitch controller. The pitch actuator is modelled as [4]:

$$
\ddot{\beta}=-\omega_{n}^{2} \beta-2 \omega_{n} \xi \dot{\beta}+\omega_{n}^{2} \beta_{u}
$$

where $\omega_{n}$ and $\xi$ are the natural frequency and the damping ratio of the pitch actuator, respectively. The pitch actuator operational ranges are limited as $\dot{\beta}_{\min } \leq \dot{\beta} \leq \dot{\beta}_{\max }, \beta_{\min } \leq \beta \leq \beta_{\max }$. Note that in this paper, $(\bullet)_{\max }$ and $(\bullet)_{\min }$ stand for the maximum and minimum allowable value of the variable $(\bullet)$, respectively. The pitch angle and its time derivative sensors are modelled as $\beta_{\mathrm{s}}=\beta+v_{\beta}, \dot{\beta}_{\mathrm{s}}=\dot{\beta}+v_{\dot{\beta}}$ and $\ddot{\beta}_{\mathrm{s}}=\ddot{\beta}+v_{\ddot{\beta}}$, where $v_{\beta}, v_{\dot{\beta}^{\prime}}$, and $v_{\ddot{\beta}}$ are the noise contents [15]. The numeric values of the wind turbine benchmark model parameters are given in Table $1[7,15]$.

Table 1. Wind turbine benchmark model parameters.

\begin{tabular}{ccccc}
\hline$\rho_{\mathrm{a}}$ & $\mathrm{R}$ & $\mathrm{J}_{\mathrm{g}}$ & $\mathrm{J}_{\mathrm{r}}$ & $\mathrm{K}_{\mathrm{dt}}$ \\
$1.225 \mathrm{~kg} / \mathrm{m}^{3}$ & $57.5 \mathrm{~m}$ & $390 \mathrm{kgm}^{2}$ & $55 \mathrm{Mkgm}^{2}$ & $2.7 \mathrm{GNm} / \mathrm{rad}$ \\
$\mathrm{B}_{\mathrm{dt}}$ & $\mathrm{B}_{\mathrm{g}}$ & $\mathrm{B}_{\mathrm{r}}$ & $\mathrm{N}_{\mathrm{g}}$ & $\eta_{\mathrm{dt}}$ \\
$945 \mathrm{kNm} /(\mathrm{rad} / \mathrm{s})$ & $3.034 \mathrm{Nm} /(\mathrm{rad} / \mathrm{s})$ & $27.8 \mathrm{kNm} /(\mathrm{rad} / \mathrm{s})$ & 95 & 0.97 \\
$\mathrm{M}_{\mathrm{t}}$ & $\mathrm{B}_{\mathrm{t}}$ & $\mathrm{K}_{\mathrm{t}}$ & $\eta_{\mathrm{g}}$ & $\omega_{\mathrm{n}}$ \\
$484 \mathrm{ton}$ & $66.7 \mathrm{~N} /(\mathrm{m} / \mathrm{s})$ & $2.55 \mathrm{MN} / \mathrm{m}$ & 0.92 & $11.11 \mathrm{rad} / \mathrm{s}$ \\
$\xi$ & $\dot{\beta}_{\min }$ & $\dot{\beta}_{\max }$ & $\beta_{\min }$ & $\beta_{\max }$ \\
0.6 & $-10^{\circ} / \mathrm{s}$ & $10^{\circ} / \mathrm{s}$ & $-2^{\circ}$ & $30^{\circ}$ \\
$\mathrm{P}_{\mathrm{g}, \mathrm{N}}$ & $\mathrm{T}_{\mathrm{g}, \mathrm{N}}$ & $\omega_{\mathrm{g}, \mathrm{N}}$ & $\omega_{\mathrm{r}, \mathrm{N}}$ & Full load region \\
$4.8 \mathrm{MW}$ & $32.107 \mathrm{kNm}$ & $162.5 \mathrm{rad} / \mathrm{s}$ & $1.71 \mathrm{rad} / \mathrm{s}$ & $12.3 \mathrm{~m} / \mathrm{s}-25 \mathrm{~m} / \mathrm{s}$ \\
$\nu_{\omega_{\mathrm{r}}}$ & $v_{\omega_{\mathrm{g}}}$ & $\nu_{\beta}$ & & \\
$0.025 \mathrm{rad} / \mathrm{s}$ & $0.0158 \mathrm{rad} / \mathrm{s}$ & $0.2^{\circ}$ & & \\
\hline \multicolumn{4}{r}{}
\end{tabular}

\section{Pitch Actuator Saturation, Faults, and Blade Aerodynamic Characteristics Change}

In reality, the achievable pitch angle range is bounded. Hence, the practical operational range of the pitch actuator is limited. So, the high wind speed variation and the consequent high pitch angle variation may lead to pitch actuator saturation, which consequently causes violation of the constrained power regulation. So, the pitch angle saturation phenomenon should be considered in the pitch angle controller design to avoid any abrupt and long-lasting saturation, and smoothly pass any possible saturation period of the pitch actuator. For the given wind turbine model, the pitch actuator saturation, $\mathrm{H}\left(\beta_{\mathrm{u}}\right)$, can be considered as:

$$
\mathrm{H}\left(\beta_{\mathrm{u}}\right)=\left\{\begin{array}{c}
\beta_{\max }, \beta_{\mathrm{u}}>\beta_{\max } \\
\beta_{\mathrm{u}}, \beta_{\min } \leq \beta_{\mathrm{u}} \leq \beta_{\max } \\
\beta_{\min }, \beta_{\mathrm{u}}<\beta_{\min }
\end{array}\right.
$$


where $\beta_{\max }=30^{\circ}$ and $\beta_{\min }=-2^{\circ}$, as in Table $1 . \mathrm{H}\left(\beta_{\mathrm{u}}\right)$ is illustrated in Figure 1 . So, this actuation saturation function is integrated into the pitch actuator mechanism (9) as:

$$
\ddot{\beta}=-\omega_{\mathrm{n}}^{2} \beta-2 \omega_{\mathrm{n}} \dot{\xi} \dot{\beta}+\omega_{\mathrm{n}}^{2} \mathrm{H}\left(\beta_{\mathrm{u}}\right) .
$$

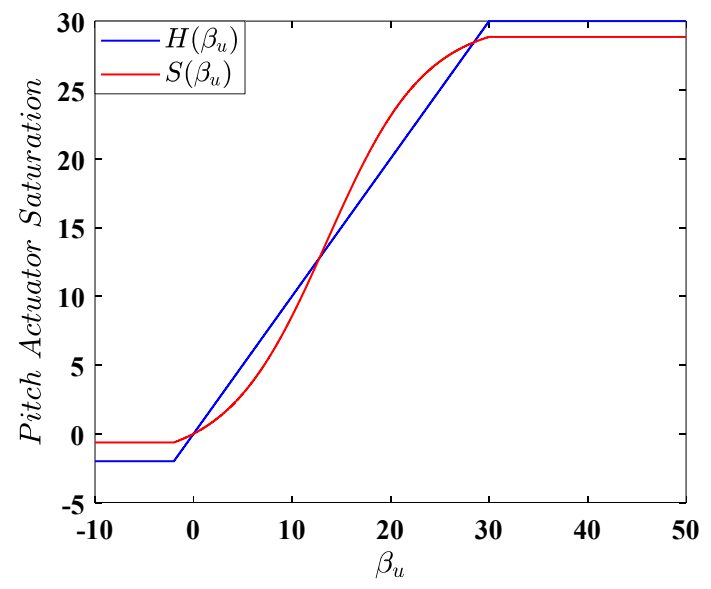

Figure 1. Pitch actuator saturation, $H\left(\beta_{u}\right)$ (blue line), and its smooth estimation, $S\left(\beta_{u}\right)$ (red line).

Obviously, this saturation function of the pitch angle is non-smooth with sharp saturation behavior, which may cause pitch actuator failure [28]. So, it is desirable to approximate this saturation behavior by a smooth function and to pass from each saturation period fluently. In this regard, the following smooth saturation function is proposed as:

$$
\mathrm{S}\left(\beta_{\mathrm{u}}\right)=\frac{\bar{\rho} \mathrm{P}-\underline{\rho}^{-1}}{\mathrm{P}+\mathrm{P}^{-1}}
$$

where $\underline{\rho}=2, \bar{\rho}=30, \mathrm{P}=\exp \left(\epsilon+\eta \beta_{\mathrm{u}}\right), \epsilon=0.5 \ln (\underline{\rho} / \bar{\rho})$, and $\eta$ is a positive constant to be selected. $\mathrm{S}\left(\beta_{\mathrm{u}}\right)$ is always in $(-\underline{\rho}, \bar{\rho})$ for all $\beta_{\mathfrak{u}} \in \mathbb{R} . \mathrm{S}\left(\beta_{\mathrm{u}}\right)$ is illustrated in Figure 1 , for $\eta=0.1$. Then, $\mathrm{H}\left(\beta_{\mathrm{u}}\right)$ can be expressed as:

$$
\mathrm{H}\left(\beta_{\mathrm{u}}\right)=\mathrm{S}\left(\beta_{\mathrm{u}}\right)+\mathrm{D}\left(\beta_{\mathrm{u}}\right),
$$

where $\mathrm{D}\left(\beta_{\mathrm{u}}\right)$ is the difference between $S\left(\beta_{\mathrm{u}}\right)$ and $\mathrm{H}\left(\beta_{\mathrm{u}}\right)$. The bounded property of the function, $\mathrm{S}\left(\beta_{\mathrm{u}}\right)$, and saturation function, $H\left(\beta_{u}\right)$, yields the function, $D\left(\beta_{u}\right)$, to be bounded as, $\left|D\left(\beta_{u}\right)\right| \leq \bar{D}_{1}$, where $\overline{\mathrm{D}}_{1}$ is a positive and unknown constant. For ease of pitch actuator controller design, the mean value theorem is employed on function $S\left(\beta_{\mathrm{u}}\right)$ to get:

$$
\mathrm{S}\left(\beta_{\mathrm{u}}\right)=\mathrm{S}\left(\beta_{0}\right)+\left.\frac{\partial \mathrm{S}}{\partial \beta_{\mathrm{u}}}\right|_{\beta_{\mathrm{m}}}\left(\beta_{\mathrm{u}}-\beta_{0}\right),
$$

where $\beta_{\mathrm{m}}=\mathrm{m} \beta_{\mathrm{u}}+(1-\mathrm{m}) \beta_{0}$ and $\mathrm{m} \in(0,1)$. By choosing $\beta_{0}=0$ and using the fact that $\mathrm{S}(0)=0$, Equation (14) becomes:

$$
S\left(\beta_{\mathrm{u}}\right)=\left.\frac{\partial \mathrm{S}}{\partial \beta_{\mathrm{u}}}\right|_{\beta_{\mathrm{m}}} \beta_{\mathrm{u}}=\mathrm{S}_{\beta_{\mathrm{u}}} \beta_{\mathrm{u}}
$$

where $S_{\beta_{u}}=2 \eta(\bar{\rho}+\underline{\rho}) /\left.\left(P+P^{-1}\right)^{2}\right|_{\beta_{m}} . S_{\beta_{u}} \in(0.2,1.65)$ for $\beta_{m} \in(-\underline{\rho}, \bar{\rho})$. Then, $S_{\beta_{u}}$ is a positive variable. Now, considering Equations (11), (13), and (15), the pitch actuator dynamic behavior with the smooth saturation function can be written as:

$$
\ddot{\beta}=-\omega_{n}^{2} \beta-2 \omega_{n} \xi \dot{\beta}+\omega_{n}^{2}\left(S_{\beta_{u}} \beta_{u}+D\left(\beta_{u}\right)\right) .
$$


Wind turbine operation in harsh offshore sites may lead to pitch actuator dynamic change, bias, and effectiveness loss. The dynamic change is because of the pressure drop due to hydraulic oil leakage, high air content in the oil, and pump wear. These dynamic change cases cause a slow pitch actuator response [7]. Consequently, power regulation in full load operation is not satisfactorily achieved. The dynamic change is considered as the change of the natural frequency and damping ratio in the pitch actuator in Equation (16). The characteristics of these changes are summarized in Table 2 [4,7], where $\mathrm{N}, \mathrm{HL}, \mathrm{PW}$, and HAC represent normal, hydraulic leaks, pump wear, and high air content situations, respectively. Also, $\omega_{n, X}$ and $\xi_{x}$ are the natural frequency and damping ratio, respectively, in the situation X. Also, $\alpha_{\mathrm{f}_{1}}$ and $\alpha_{\mathrm{f}_{2}}$ are fault indicators.

Table 2. Pitch actuator dynamic change (Data from [4]).

\begin{tabular}{cccc}
\hline Situation & Fault Indicator & $\omega_{\mathbf{n}}$ & $\xi$ \\
\hline Normal Situation & $\alpha_{\mathrm{f}_{1}}=\alpha_{\mathrm{f}_{2}}=0$ & $\omega_{\mathrm{n}, \mathrm{N}}=11.11(\mathrm{rad} / \mathrm{s})$ & $\xi_{\mathrm{N}}=0.6$ \\
Pump Wear & $\alpha_{\mathrm{f}_{1}}=0.6316, \alpha_{\mathrm{f}_{2}}=0.29688$ & $\omega_{\mathrm{n}, \mathrm{PW}}=7.27(\mathrm{rad} / \mathrm{s})$ & $\xi_{\mathrm{PW}}=0.75$ \\
Hydraulic Leak & $\alpha_{\mathrm{f}_{1}}=1, \alpha_{\mathrm{f}_{2}}=0.87853$ & $\omega_{\mathrm{n}, \mathrm{HL}}=3.42(\mathrm{rad} / \mathrm{s})$ & $\xi_{\mathrm{HL}}=0.9$ \\
High Air Content & $\alpha_{\mathrm{f}_{1}}=0.81083, \alpha_{\mathrm{f}_{2}}=1$ & $\omega_{\mathrm{n}, \mathrm{HAC}}=5.73(\mathrm{rad} / \mathrm{s})$ & $\xi_{\mathrm{HAC}}=0.45$ \\
\hline
\end{tabular}

The dynamic change case effects are illustrated in Figure 2, where the initial pitch angle is set to $5^{\circ}$ and $\beta_{\mathrm{u}}=0^{\circ}$. It is obvious that the response for all dynamic change cases is slower than the normal one.

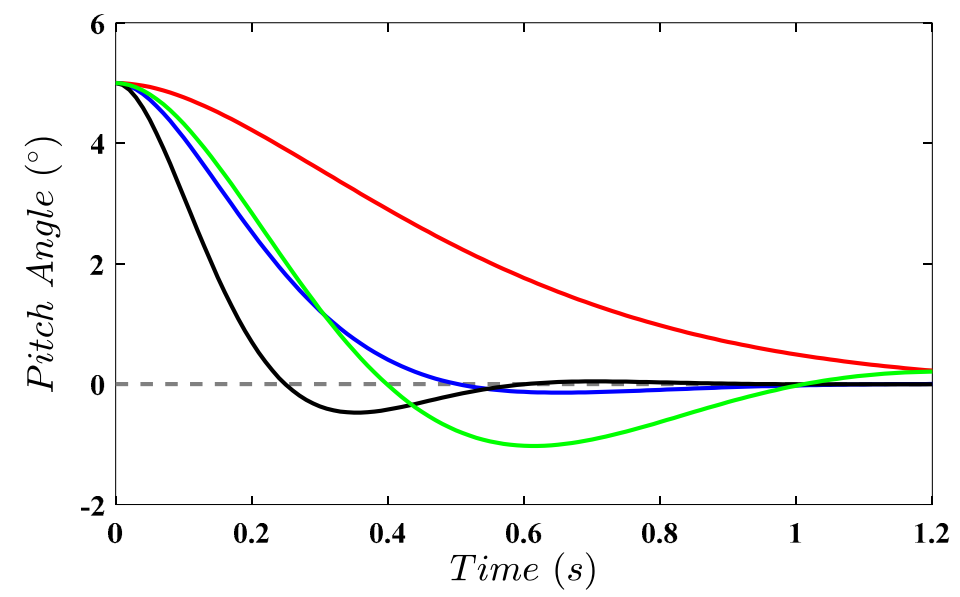

Figure 2. Pitch actuator response in situations: normal (black line), hydraulic leak (red line), pump wear (blue line), and high air content (green line).

The dynamic change is modelled as an uncertainty, which should be attenuated by the pitch angle controller. The dynamic changes are modelled as a convex function of the normal natural frequency and normal damping ratio [18]. So, the pitch actuator (Equation (16)) is rewritten, including the dynamic change effect, i.e., added as an uncertainty in the model, as:

$$
\ddot{\beta}=-\omega_{n, N}^{2} \beta-2 \omega_{n, N} \xi_{N} \dot{\beta}+\omega_{n, N}^{2}\left(S_{\beta_{u}} \beta_{u}+D\left(\beta_{u}\right)\right)+\Delta \widetilde{f}_{P A D}
$$

where $\Delta \widetilde{\mathrm{f}}_{\mathrm{PAD}}=-\alpha_{\mathrm{f}_{1}} \Delta\left(\widetilde{\omega}_{\mathrm{n}}^{2}\right) \beta-2 \alpha_{\mathrm{f}_{2}} \Delta\left(\widetilde{\omega}_{\mathrm{n}} \widetilde{\xi}\right) \dot{\beta}+\alpha_{\mathrm{f}_{1}} \Delta\left(\widetilde{\omega}_{\mathrm{n}}^{2}\right) \beta_{\mathrm{u}}, \Delta\left(\widetilde{\omega}_{\mathrm{n}}^{2}\right)=\widetilde{\omega}_{\mathrm{n}, \mathrm{HL}}^{2}-\widetilde{\omega}_{\mathrm{n}, \mathrm{N}}^{2}$ and $\Delta\left(\widetilde{\omega}_{\mathrm{n}} \tilde{\xi}\right)=$ $\omega_{\mathrm{n}, \mathrm{HAC}} \xi_{\mathrm{HAC}}-\omega_{\mathrm{n}, \mathrm{N}} \xi_{\mathrm{N}}$.

The pitch actuator output can be corrupted by an unanticipated fault, modelled as an additive bias and/or effectiveness loss. These faults deviate the pitch angle from the desired one [16]. These faults are modelled as:

$$
\beta_{\mathrm{u}}(\mathrm{t})=\rho(\mathrm{t}) \beta_{\text {ref }}(\mathrm{t})+\Phi(\mathrm{t}),
$$


where $\Phi(t)$ represents the unknown pitch actuator bias [29]. Also, $\rho(t)$ is the unknown effectiveness of the actuator, which is $0<\rho(t) \leq 1$, where $\rho(t)=1$ indicates full effectiveness of the pitch actuator and $\rho(t)=0$ is total actuator loss [13,29]. $\beta_{\text {ref }}(t)$ is the reference pitch angle, which is designed by the pitch controller. It is obvious that in the case of full pitch actuator effectiveness and no pitch bias, $\beta_{\mathrm{u}}(\mathrm{t})=\beta_{\text {ref }}(\mathrm{t})$. The pitch actuator dynamic behavior, Equation (17), associated with pitch actuator bias and effectiveness loss, can be rewritten as:

$$
\ddot{\beta}=-\omega_{n, N}{ }^{2} \beta-2 \omega_{n, N} \xi_{N} \dot{\beta}+\omega_{n, N}^{2}\left(S_{\beta_{u}} \rho(t) \beta_{\text {ref }}+S_{\beta_{u}} \Phi(t)+D\left(\beta_{u}\right)\right)+\Delta \widetilde{f}_{P A D} .
$$

The wind turbine operation in the presence of rain, snow, and dirt leads to blade erosion or debris build-up, which, in turn, leads to a blade aerodynamic efficiency reduction. Consequently, the captured aerodynamic power is decreased. On the other hand, the power regulation is not satisfactorily achieved due to the changed blade aerodynamic profile. The debris build-up effect is modelled as an aerodynamic change, $\Delta T_{a, \Delta C_{p}}$, due to a change in the power coefficient as $\widetilde{C}_{p}=C_{p}+\Delta C_{p}$. So, it is very important to foresee this potential change in the controller design. It is worth noting that debris build-up is challenging to detect, as it is hard to identify if the reason for the reduced power is the blade's debris or simply that the wind speed has decreased. As debris build-up occurs slowly, this change is mostly assumed to lie within the annual maintenance/inspection, in which the blades are cleaned/replaced. So, this paper aims to design a pitch controller that is insensitive to debris build-up that guarantees graceful degradation up to the next planned maintenance of the blades.

\section{Desired Operational Mode and Control Objectives}

As mentioned earlier in Section 1, in the full load region, it is desirable to keep $\mathrm{P}_{\mathrm{g}}$ at the nominal value, $\mathrm{P}_{\mathrm{g}, \mathrm{N}}$, to avoid overspeeding and consequent brake engagement. To this aim, by taking Equation (8) into account, (i) $T_{g}$ is to be kept at the nominal value, $T_{g, N}$, and (ii) $\omega_{g}$ is to be kept at the nominal value, $\omega_{g, N}$, to have nominal power generation as, $P_{g}=\eta_{g} T_{g} \omega_{g}=\eta_{g} T_{g, N} \omega_{g, N}=P_{g, N}[7]$. Considering the fast response of the electrical generator, the objective (i) is achieved via tuning the generator reference torque at $\mathrm{T}_{\mathrm{g}, \mathrm{N}}$, which leads $\mathrm{T}_{\mathrm{g}}$ to be set to $\mathrm{T}_{\mathrm{g}, \mathrm{N}}$ quickly. The objective (ii) is achieved by adjusting $\beta$ of the pitch actuator. This leads to tuning the aerodynamic torque, and consequently, the rotor speed and the generator speed [4]. The wind speed is a highly stochastic variable. So, accurate nominal power generation is very challenging, and in the case of improper controller design, it may lead to overspeeding and braking. So, it is very beneficial to guarantee that the generated power and speed do not violate the given constraint, within which the mechanical brake is not engaged. It should be noted that for the power control purpose, the generator torque controller is not active. So, the faults in the generator are not considered in this paper and it is assumed that generator faults have already been accommodated for using the generator controller [4].

The controller is designed to adjust the reference pitch angle, $\beta_{\text {ref }}$, and keep the rotor speed as close as possible to the nominal one, i.e., $\omega_{\mathrm{r}, \mathrm{N}}$, never violating the given constraint, in the presence of wind speed variation, disturbance, and pitch actuator faults and saturation. The primary objective of this paper consists of satisfying the above-mentioned requirements.

By considering structurally safe operation of the wind turbine, it is desirable to keep the drive train torsion angle variation, $\dot{\theta}_{\Delta}$, as small as possible, which in turn leads to the drive train stress reduction. Accordingly, $\dot{\theta}_{\Delta}=0$ leads to $\mathrm{N}_{\mathrm{g}} \omega_{\mathrm{r}}=\omega_{\mathrm{g}}$ [17]. So, it is beneficial to keep the ratio between the rotor and generator speeds at the drive train ratio [14]. As the generator speed has to follow the signal, $\omega_{\mathrm{g}, \mathrm{N}}$, then the rotor speed is kept at $\omega_{\mathrm{r}, \mathrm{N}}=\omega_{\mathrm{g}, \mathrm{N}} / \mathrm{N}_{\mathrm{g}}$ [6]. Moreover, the condition, $\dot{\theta}_{\Delta}=0$, with zero initial drive train torsion angle, leads to $\theta_{\Delta}=0$, i.e., the reduced drive train stress trajectory [6]. Accordingly, considering Equation (7), the desirable operational mode of the wind turbine with reduced drive train stress is given by $[6,14]$ :

$$
\dot{\omega}_{\mathrm{r}}=\mathrm{a}_{1} \omega_{\mathrm{r}}+\mathrm{a}_{2} \omega_{\mathrm{g}}+\mathrm{a}_{3} \mathrm{~T}_{\mathrm{a}}, \dot{\omega}_{\mathrm{g}}=\mathrm{b}_{1} \omega_{\mathrm{r}}+\mathrm{b}_{2} \omega_{\mathrm{g}}+\mathrm{b}_{3} \mathrm{~T}_{\mathrm{g}}
$$


where, $\mathrm{a}_{1}=-\left(\mathrm{B}_{\mathrm{dt}}+\mathrm{B}_{\mathrm{r}}\right) / \mathrm{J}_{\mathrm{r}}, \mathrm{a}_{2}=\mathrm{B}_{\mathrm{dt}} / \mathrm{N}_{\mathrm{g}} \mathrm{J}_{\mathrm{r}}, \mathrm{a}_{3}=1 / \mathrm{J}_{\mathrm{r}}, \mathrm{b}_{1}=\eta_{\mathrm{dt}} \mathrm{B}_{\mathrm{dt}} / \mathrm{N}_{\mathrm{g}} \mathrm{J}_{\mathrm{g}}, \mathrm{b}_{2}=\left(-\eta_{\mathrm{dt}} \mathrm{B}_{\mathrm{dt}} / \mathrm{N}_{\mathrm{g}}{ }^{2}-\mathrm{B}_{\mathrm{g}}\right) / \mathrm{J}_{\mathrm{g}}$, $\mathrm{b}_{3}=-1 / \mathrm{J}_{\mathrm{g}}$. Consequently, (20) can be rewritten as,

$$
\ddot{\omega}_{\mathrm{r}}=\mathrm{c}_{1} \omega_{\mathrm{r}}+\mathrm{c}_{2} \omega_{\mathrm{g}}+\mathrm{c}_{3} \mathrm{~T}_{\mathrm{a}}+\mathrm{c}_{4} \mathrm{~T}_{\mathrm{g}}+\mathrm{a}_{3} \dot{\mathrm{T}}_{\mathrm{a}}
$$

where $c_{1}=a_{1}^{2}+a_{2} b_{1}, c_{2}=a_{1} a_{2}+a_{2} b_{2}$, and $c_{3}=a_{1} a_{3}, c_{4}=a_{2} b_{3}$. Considering Equations (1) and (21), it is obvious that the rotor speed is controlled by regulating the pitch angle and the consequent aerodynamic torque. In this paper, it is assumed that at any operational point of the wind turbine, $T_{a}$ is not a singular function. Also, for any pair of $\left(V_{r}, \omega_{r}\right)$, there is a given pitch angle, i.e., $\beta^{*}$, leading to the nominal power generation [9]. So, in the presence of wind speed variations, $\beta^{*}$ will be set to the value that satisfies the control objective. For the considered benchmark model, the $\beta^{*}$ diagram is illustrated in Figure 3 [7]. Note that as the wind speed is considered an uncertain disturbance, then $\beta^{*}$ is an unknown variable.

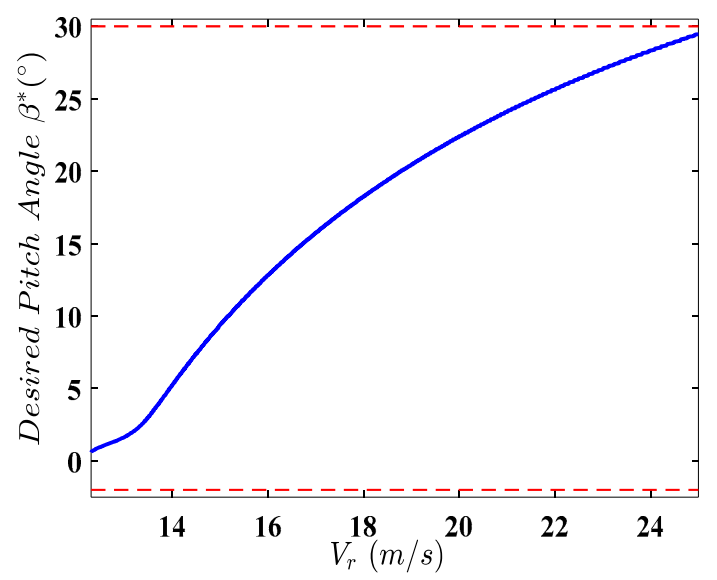

Figure 3. Diagram of $\beta^{*}$ (blue line), and lower and upper pitch angle bounds (red dashed lines).

It is obvious that the rotor dynamic behavior (Equation (21)) is a non-affine function of the pitch angle [9]. Linearization is one obvious solution. However, it would lead to high inaccuracy. So, the paper solved this problem by using the mean value theorem in this paper. As stated earlier, $T_{a}$ is not a singular function for any triple pair $\left(V_{r}, \omega_{r}, \beta\right)$ in the operational range of the wind turbine. So, according to the mean value theorem, for any given pair of $\left(V_{r}, \omega_{r}\right)$, there exists $\Xi \in(0,1)$, such that [9]:

$$
\mathrm{T}_{\mathrm{a}}\left(\mathrm{V}_{\mathrm{r}}, \omega_{\mathrm{r}}, \beta\right)=\mathrm{T}_{\mathrm{a}}\left(\mathrm{V}_{\mathrm{r}}, \omega_{\mathrm{r}}, \beta^{*}\right)+\left.\left(\beta-\beta^{*}\right) \frac{\partial \mathrm{T}_{\mathrm{a}}}{\partial \beta}\right|_{\left(\mathrm{V}_{\mathrm{r}}, \omega_{\mathrm{r}}, \beta_{\mathrm{k}}\right)^{\prime}}
$$

where $\beta_{k}=\Xi \beta+(1-\Xi) \beta^{*}$. Using $T_{a}$ in Equation (1) and $C_{p}$ in Equation (4), for the considered wind turbine model, whose parameter values are given in Table 1 , the diagram of $\partial \mathrm{T}_{\mathrm{a}} / \partial \beta$ in the full load region is shown in Figure 4.

Remark 1. In Figure 4, it is evident that $-L \leq \partial T_{a} / \partial \beta \leq-U<0$, with $0<U<L$. This means that as the wind speed increases, by increasing the pitch angle, the aerodynamic torque decreases.

Taking the time derivative of Equation (22) yields:

$$
\dot{\mathrm{T}}_{\mathrm{a}}\left(\mathrm{V}_{\mathrm{w}}, \omega_{\mathrm{r}}, \beta\right)=\Delta \mathrm{T}_{\mathrm{a}, \Delta \mathrm{C}_{\mathrm{p}}}+\dot{\beta} \frac{\partial \mathrm{T}_{\mathrm{a}}}{\partial \beta}=\Delta \mathrm{T}_{\mathrm{a}, \Delta \mathrm{C}_{\mathrm{p}}}+\dot{\beta} \mathrm{T}_{\mathrm{a}, \beta},
$$

where $\Delta \mathrm{T}_{\mathrm{a}, \Delta \mathrm{C}_{\mathrm{p}}}=\mathrm{dT}_{\mathrm{a}}\left(\mathrm{V}_{\mathrm{r}}, \omega_{\mathrm{r}}, \beta^{*}\right) / \mathrm{dt}+\left(\beta-\beta^{*}\right) \mathrm{d}\left(\partial \mathrm{T}_{\mathrm{a}} / \partial \beta\right) /\left.\mathrm{dt}\right|_{\left(\mathrm{V}_{\mathrm{r}}, \omega_{\mathrm{r}}, \beta_{\mathrm{k}}\right)}-\left.\left(\mathrm{d} \beta^{*} / \mathrm{dt}\right)\left(\partial \mathrm{T}_{\mathrm{a}} / \partial \beta\right)\right|_{\left(\mathrm{V}_{\mathrm{r}}, \omega_{\mathrm{r}}, \beta_{\mathrm{k}}\right)}$ and $\partial \mathrm{T}_{\mathrm{a}} / \partial \beta=\mathrm{T}_{\mathrm{a}, \beta} . \Delta \mathrm{T}_{\mathrm{a}, \Delta \mathrm{C}_{\mathrm{p}}}$ is due to $\Delta \mathrm{C}_{\mathrm{p}}$, which is the result of the changes in the blade aerodynamic characteristics. The debris build-up and erosion occur slower than the mean time to the maintenance of the 
blades. So, all terms that are contributing to $\Delta \mathrm{T}_{\mathrm{a}, \Delta \mathrm{C}_{\mathrm{p}}}$ are assumed to be bounded, then $\Delta \mathrm{T}_{\mathrm{a}, \Delta \mathrm{C}_{\mathrm{p}}}$ is bounded as $\left|\Delta \mathrm{T}_{\mathrm{a}, \Delta \mathrm{C}_{\mathrm{p}}}\right| \leq \overline{\mathrm{k}}_{1}$, where $\overline{\mathrm{k}}_{1}$ is an unknown positive constant. Also, it should be noted that as the wind speed is not accurately measurable, $T_{a, \beta}$ in Equation (23) is an unknown variable. Substituting Equation (23) into Equation (21) leads to:

$$
\ddot{\omega}_{\mathrm{r}}=\mathrm{c}_{1} \omega_{\mathrm{r}}+\mathrm{c}_{2} \omega_{\mathrm{g}}+\mathrm{c}_{3} \mathrm{~T}_{\mathrm{a}}+\mathrm{c}_{4} \mathrm{~T}_{\mathrm{g}}+\mathrm{a}_{3}\left(\Delta \mathrm{T}_{\mathrm{a}, \Delta \mathrm{c}_{\mathrm{p}}}+\dot{\beta} \mathrm{T}_{\mathrm{a}, \beta}\right) .
$$

Now, by considering Equation (19), the rotor dynamic behavior (Equation (24)) can be rewritten as:

$$
\begin{aligned}
& \ddot{\omega}_{\mathrm{r}}=c_{1} \omega_{\mathrm{r}}+ \mathrm{c}_{2} \omega_{\mathrm{g}}+\mathrm{c}_{3} \mathrm{~T}_{\mathrm{a}}+\mathrm{c}_{4} \mathrm{~T}_{\mathrm{g}}-\frac{\mathrm{a}_{3} \omega_{\mathrm{n}, \mathrm{N}} \beta \mathrm{T}_{\mathrm{a}, \beta}}{2 \varepsilon_{\mathrm{N}}}-\frac{\mathrm{a}_{3} \ddot{\beta} \mathrm{T}_{\mathrm{a}, \beta}}{2 \omega_{\mathrm{n}, \mathrm{s}} \xi_{\mathrm{N}}}+\frac{\mathrm{a}_{3} \mathrm{~S}_{\beta_{\mathrm{u}}} \omega_{\mathrm{n}, \mathrm{N}} \rho \mathrm{T}_{\mathrm{a}, \beta}}{2 \varepsilon_{\mathrm{N}}} \beta_{\mathrm{ref}}+ \\
& \frac{\mathrm{a}_{3} \omega_{\mathrm{n}, \mathrm{N}} \mathrm{DT}_{\mathrm{a}, \beta}}{2 \xi_{\mathrm{N}}}+\mathrm{a}_{3} \Delta \mathrm{T}_{\mathrm{a}, \Delta \mathrm{c}_{\mathrm{p}}}+\frac{\mathrm{a}_{3} \mathrm{~T}_{\mathrm{a}, \beta}}{2 \xi_{\mathrm{N}}}\left(\frac{\widetilde{\Delta \mathrm{f}_{\mathrm{PAD}},}}{\omega_{\mathrm{n}, \mathrm{N}}}+\mathrm{S}_{\beta_{\mathrm{u}}} \omega_{\mathrm{n}, \mathrm{N}} \Phi\right) .
\end{aligned}
$$

This expression describes the wind turbine rotor dynamic behavior in the desired operational mode, which takes into account possible pitch actuator dynamic changes. Also, smooth pitch angle saturation is included.

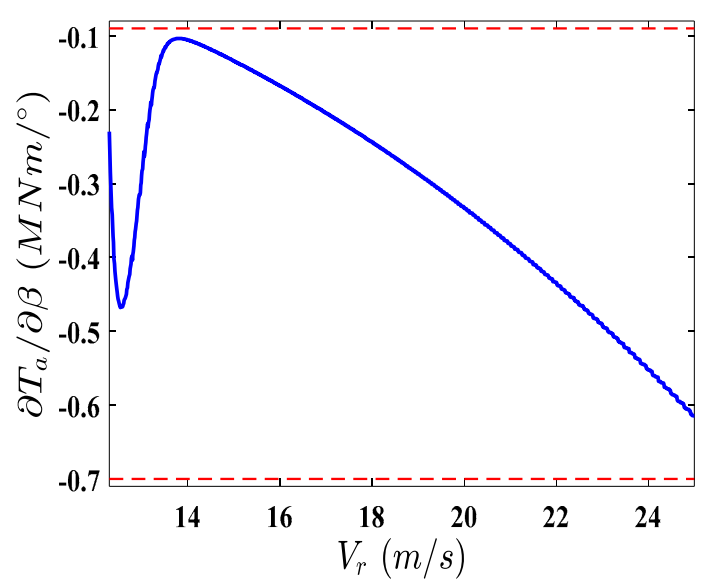

Figure 4. $\partial \mathrm{T}_{\mathrm{a}} / \partial \beta$ diagram in full load operation (blue line), and upper and lower bounds (red dashed lines).

\section{Constrained Fault-Tolerant Controller Design and Stability Analysis}

In this section, the constrained fault-tolerant pitch controller is designed to guarantee that the generated power is kept within given constraints, in the presence of wind speed variation, disturbance, faults, and saturation. The robust stability of the wind turbine closed-loop system with the proposed controller is proved. First, some technical preliminaries are provided, which will be used for the controller design.

\subsection{Technical Preliminaries}

The wind speed is uncertain as the wind speed is measured with an anemometer, usually placed at the back of the nacelle. Therefore, its measurement is affected by the turbulence generated by the rotor. So, the wind speed is considered as an uncertain disturbance. Accordingly, the aerodynamic torque, $\mathrm{T}_{\mathrm{a}}$, is not accurately available. On the other hand, $\mathrm{T}_{\mathrm{a}}$ is contributing to the rotor dynamic response (Equation (25)). So, $\mathrm{T}_{\mathrm{a}}$ should be estimated to be used in the proposed controller structure. In this paper, an RBF neural network is designed to estimate the aerodynamic torque [30]. To this end, $\mathrm{T}_{\mathrm{a}}$ is approximated as $[9,31]$ :

$$
\mathrm{T}_{\mathrm{a}}(\mathbf{Z})=\theta^{* \mathrm{~T}} \mathbf{h}(\mathbf{Z})+\varepsilon,
$$


where $\theta^{*}$ is the optimal weight vector, $\mathbf{h}(\mathbf{Z})=\left[\mathrm{h}_{1}(\mathbf{Z}), \mathrm{h}_{2}(\mathbf{Z}), \ldots, \mathrm{h}_{\mathrm{s}}(\mathbf{Z})\right]^{\mathrm{T}} \in \mathbb{R}^{\mathrm{s}}$ is the known basis function vector, $s>1$ is the number of neural network nodes, $\mathbf{Z}=\left[\mathrm{T}_{\mathrm{g}}, \omega_{\mathrm{g}}, \beta\right]^{\mathrm{T}} \in \Omega_{\mathbf{Z}}, \varepsilon \in \mathbb{R}$ is the approximation error, and $h_{i}(\mathbf{Z})$ is selected as a Gaussian function given by $[9,21]$ :

$$
h_{i}(\mathbf{Z})=\exp \left(\frac{-\left(\mathbf{Z}-\vartheta_{\mathbf{i}}\right)^{\mathrm{T}}\left(\mathbf{Z}-\vartheta_{\mathbf{i}}\right)}{2 \varphi_{i}^{2}}\right),
$$

where $\vartheta_{i}=\left[\vartheta_{i, T_{g}}, \vartheta_{i, \omega_{g}}, \vartheta_{i, \beta}\right]^{T}$ is the $i^{\text {th }}$ centre vector of the inputs, as $i=1, \ldots, \mathrm{s} . \varphi_{c}=\left[\varphi_{1}, \ldots, \varphi_{s}\right]^{T}$ is the width vector of the Gaussian functions [32]. $T_{a, N N}$ is the approximation of $T_{a}$ provided by the RBF, described as:

$$
\mathrm{T}_{\mathrm{a}, \mathrm{NN}}(\mathbf{Z})=\theta^{\mathrm{T}} \mathbf{h}(\mathbf{Z})
$$

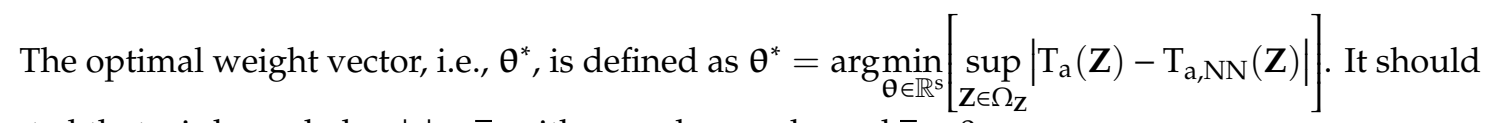
be noted that $\varepsilon$ is bounded as $|\varepsilon| \leq \bar{\varepsilon}$, with an unknown bound, $\bar{\varepsilon}>0$.

Now, the following definitions and lemmas are given, which will be used in the proposed controller design.

As $T_{a, \beta}$ is an unknown variable, contributing to the gain of $\beta_{\text {ref }}$ in Equation (25), this leads to the unknown control direction problem. To tackle this issue in the controller design, the Nussbaum-type function is utilized, which is defined as follows.

Definition 1 [16]. A Nussbaum-type function, $N(\xi(t))$, is a smooth continuous even function, such that it satisfies $\lim _{r \rightarrow \infty} \sup \frac{1}{r} \int_{0}^{r} N(\xi) d \xi=+\infty$ and $\lim _{r \rightarrow \infty} \inf \frac{1}{r} \int_{0}^{r} N(\xi) d \xi=-\infty$.

The BLF function is defined as follows, which is used in the constrained control construction.

Definition 2 [32]. If the scalar function, $V(x)$, is positive definite continuous with respect to the solution of the system, $\dot{x}=f(x)$, on an open region, $\mathcal{D}$, then $V(x)$ is a BLF with continuous first-order partial derivatives within all $\mathcal{D}$. As $x$ approaches the boundary of the region, $\mathcal{D}$, then $V(x)$ approaches infinity. Finally, $V(x)$ satisfies $V(x) \leq \sqsupseteq, \forall t \geq 0$ along the solution of $\dot{x}=f(x)$ for $x(0) \in \mathcal{D}$, and some positive constant, $\sqsupseteq$.

The following definition is given for the boundedness of the closed-loop system.

Definition 3 [32]. The solution of a system, $x(t)$, is uniformly ultimately bounded (UUB) if there exists a number, $T\left(K, x\left(t_{0}\right)\right)$, and $a K>0$ such that for any compact set, $\mathcal{S}$, and all $x\left(t_{0}\right) \in \mathcal{S},\|x(t)\| \leq K$, for all $t \geq t_{0}+T$.

Lemma 1 [33]. Let us assume that $V(t)>0$ and $\xi(t)$ are smooth functions for any $t \in\left[0 t_{f}\right)$. Also, $N(\xi(t))$ is a Nussbaum-type function. Then, if $V(t)<c_{0}+\exp \left(-c_{1} t\right) \int_{0}^{t}(g(\tau) N(\xi(\tau))+1) \dot{\xi} e^{c_{1} \tau} d \tau$ holds true, where $c_{0}$ and $c_{1}$ are positive constants, and $g(\tau)$ takes values in unknown closed intervals, $L \in\left[l^{+}, l^{-}\right]$with $0 \notin L$, then $V(t), \xi(t)$, and $\int_{0}^{t} g(\tau) N(\xi(\tau)) \dot{\xi} \exp \left(c_{1} \tau\right) d \tau$ must be bounded on $\left[0 t_{f}\right)$.

Lemma 2 [33]. If the Lyapunov function, $V(t)>0$, satisfies $\dot{V}<-b_{1} V+b_{2}$, where $b_{1}$ and $b_{2}$ are positive constants, then the solution of the closed-loop system is UUB for bounded initial conditions.

Lemma 3 [34]. For variable, $\psi$, in $|\psi|<1, \tan \left(\pi \psi^{2} / 2\right)<\pi \psi^{2} \sec ^{2}\left(\pi \psi^{2} / 2\right)$ holds true.

Lemma 4 [34]. For any variable, $\Psi$, and any positive constant, $\gamma, 0<|\Psi|-\Psi \tanh (\Psi / \gamma)<K \gamma$ holds true, where $K$ satisfies $K=\exp (-(K+1))$, accordingly, $K=0.2785$. Also, as $\Psi \tanh (\Psi / \gamma)>0$, then for any variable, $<-1, \Psi \tanh (\Psi / \gamma)<-\Psi \tanh (\Psi / \gamma)$ holds. 
Lemma 5 [25]. For any positive constant, $\sigma$, and considering the definition, $\widetilde{a}=\hat{a}-a,-\sigma \widetilde{a} \hat{a} \leq-\sigma \widetilde{a}^{2} / 2+\sigma a^{2} / 2$ holds true for any variables, $a \in \mathbb{R}$ and $\hat{a} \in \mathbb{R}$. This relation is modified for vectors as, $-\sigma \widetilde{\boldsymbol{b}}^{T} \hat{\boldsymbol{b}} \leq-\sigma\|\widetilde{\boldsymbol{b}}\|^{2} / 2+\sigma\|\boldsymbol{b}\|^{2}$, where, $\widetilde{\boldsymbol{b}}=\hat{\boldsymbol{b}}-\boldsymbol{b}$ for any vectors, $\boldsymbol{b} \in \mathbb{R}^{n}$ and $\hat{\boldsymbol{b}} \in \mathbb{R}^{n}$.

\subsection{Controller Design Procedure}

The main objective of the designed controller is to keep the rotor speed and acceleration within constraints, which in turn leads to bounded power generation around the nominal one. The proposed controller design requires the definition of the rotor speed tracking error and its time derivative as follows:

$$
\mathrm{e}_{1}=\omega_{\mathrm{r}, \mathrm{s}}-\omega_{\mathrm{r}, \mathrm{d}}, \mathrm{e}_{2}=\dot{\omega}_{\mathrm{r}, \mathrm{s}}-\mathrm{z}_{2},
$$

where $\omega_{r, d}$ is the desired rotor speed. As stated earlier, $\omega_{r, d}$ in the full load region is $\omega_{r, N} \cdot z_{2}$ is a virtual control. Here, to avoid repetitive differentiation of $z_{2}$, which increases the implementation complexity, the DSC technique is utilized, which requires the filtering of $z_{2}$ by means of a stabilizing function, $\alpha_{1}$, to be determined. Let $\alpha_{1}$ pass through a first-order filter with a time constant, $\tau_{2}$, defined as:

$$
\tau_{2} \dot{\mathrm{z}}_{2}+\mathrm{z}_{2}=\alpha_{1}, \mathrm{z}_{2}(0)=\alpha_{1}(0)
$$

The output error of the first-order filter is $\chi_{2}=z_{2}-\alpha_{1}$ with its first-time derivative, $\dot{z}_{2}=-\chi_{2} / \tau_{2}$. A Lyapunov function is chosen as:

$$
\mathrm{V}_{1}=\frac{\mathrm{k}_{\mathrm{e}_{1}}^{2}}{\pi} \tan \Lambda_{1}+\frac{1}{2} \chi_{2}^{2}
$$

where $\Lambda_{1}=\pi \xi_{1}^{2} / 2, \xi_{1}=e_{1} / k_{e_{1}}$, whilst $k_{e_{1}}$ represents a constraint on $\mathrm{e}_{1}$. It should be noted that $\mathrm{V}_{1}$ is continuous in the set $\Omega_{e_{1}}=\left\{\mathrm{e}_{1}:-\mathrm{k}_{\mathrm{e}_{1}}<\mathrm{e}_{1}<\mathrm{k}_{\mathrm{e}_{1}}\right\}$. $\mathrm{V}_{1}$ is positive definite and its first term captures the BLF characteristics of the modified tracking error, $\xi_{1}$, according to Definition 2. The first-time derivative of $\xi_{1}$ is obtained as:

$$
\dot{\xi}_{1}=\frac{\dot{\mathrm{e}}_{1}}{\mathrm{k}_{\mathrm{e}_{1}}}=\frac{\mathrm{e}_{2}+\chi_{2}+\alpha_{1}}{\mathrm{k}_{\mathrm{e}_{1}}} .
$$

On the other hand, the first-time derivative of Equation (31) can be obtained as:

$$
\dot{\mathrm{V}}_{1}=\mathrm{e}_{1} \mathrm{e}_{2} \sec ^{2} \Lambda_{1}+\mathrm{e}_{1} \chi_{2} \sec ^{2} \Lambda_{1}+\mathrm{e}_{1} \alpha_{2} \sec ^{2} \Lambda_{1}-\frac{\chi_{2}^{2}}{\tau_{2}}-\dot{\alpha}_{1} \chi_{2} .
$$

The virtual control, $\alpha_{1}$, is designed as:

$$
\alpha_{1}=-\gamma_{1} \mathrm{e}_{1}-\mathrm{e}_{1} \sec ^{2} \Lambda_{1}
$$

where, $\gamma_{1}$ is a positive design parameter. The substitution of Equation (34) into Equation (33) yields:

$$
\dot{\mathrm{V}}_{1}=\mathrm{e}_{1} \mathrm{e}_{2} \sec ^{2} \Lambda_{1}+\mathrm{e}_{1} \chi_{2} \sec ^{2} \Lambda_{1}-\gamma_{1} \mathrm{e}_{1}^{2} \sec ^{2} \Lambda_{1}-\mathrm{e}_{1}^{2} \sec ^{4} \Lambda_{1}-\frac{\chi_{2}^{2}}{\tau_{2}}-\dot{\alpha}_{1} \chi_{2} .
$$

Considering Young's inequality:

$$
\mathrm{e}_{1} \mathrm{e}_{2} \sec ^{2} \Lambda_{1} \leq \frac{1}{2} \mathrm{e}_{1}^{2} \sec ^{4} \Lambda_{1}+\frac{1}{2} \mathrm{e}_{2}^{2}, \mathrm{e}_{1} \chi_{2} \sec ^{2} \Lambda_{1} \leq \frac{1}{2} \mathrm{e}_{1}^{2} \sec ^{4} \Lambda_{1}+\frac{1}{2} \chi_{2}^{2} .
$$

Since $\alpha_{1}$ is a function of $\omega_{\mathrm{r}}, \omega_{\mathrm{r}, \mathrm{d}}$, and $\dot{\omega}_{\mathrm{r}, \mathrm{d}}$, it can be shown that:

$$
\dot{\alpha}_{1}=\frac{\partial \alpha_{1}}{\partial \omega_{\mathrm{r}}} \dot{\omega}_{\mathrm{r}}+\frac{\partial \alpha_{1}}{\partial \omega_{\mathrm{r}, \mathrm{d}}} \dot{\omega}_{\mathrm{r}, \mathrm{d}}+\frac{\partial \alpha_{1}}{\partial \dot{\omega}_{\mathrm{r}, \mathrm{d}}} \ddot{\omega}_{\mathrm{r}, \mathrm{d}} .
$$


Considering Equation (37), $\dot{\alpha}_{1}$ is a continuous function. Then, given $\delta_{\omega_{\mathrm{r}, \mathrm{d}}}$ and any positive number, $\delta_{1}$, the set, $\Omega_{\omega_{\mathrm{r}, \mathrm{d}}}:=\left\{\omega_{\mathrm{r}, \mathrm{d}} \in \mathbb{R}: \omega_{\mathrm{r}, \mathrm{d}}^{2}+\dot{\omega}_{\mathrm{r}, \mathrm{d}}^{2}+\ddot{\omega}_{\mathrm{r}, \mathrm{d}}^{2}<\delta_{\omega_{\mathrm{r}, \mathrm{d}}}\right\}$, for all initial conditions satisfying $\Omega_{1}:=\left\{\left[\mathrm{e}_{1}, \chi_{2}\right]^{\mathrm{T}}:\left(\mathrm{k}_{\mathrm{e}_{1}}^{2} \tan \Lambda_{1}\right) / \pi+\chi_{2}^{2} / 2<\delta_{1}\right\}$ is compact [25]. Thus, $\dot{\alpha}_{1}$ has a maximum constant value, $\mathrm{M}_{1}$, in the compact set, $\Omega_{\omega_{\mathrm{r}, \mathrm{d}}} \times \Omega_{1}$, for given initial conditions [28]. So, based on Young's inequality:

$$
\left|\dot{\alpha}_{1} \chi_{2}\right| \leq \frac{1}{2} \chi_{2}^{2}+\frac{1}{2} M_{1}^{2}
$$

According to Equations (36) and (38), Equation (35) can be rewritten as:

$$
\dot{\mathrm{V}}_{1}<-\gamma_{1} \mathrm{e}_{1}^{2} \sec ^{2} \Lambda_{1}-\frac{1}{2} \chi_{2}^{2}\left(2 / \tau_{2}-2\right)+\frac{1}{2} \mathrm{M}_{1}^{2}+\frac{1}{2} \mathrm{e}_{2}^{2} .
$$

The parameter, $\tau_{2}$, is selected as $\tau_{2}<1$ to satisfy $\left(2 / \tau_{2}-2\right)>0$. Also, considering Lemma 3 , $-\gamma_{1} \mathrm{e}_{1}^{2} \sec ^{2} \Lambda_{1}<-\left(\gamma_{1} \mathrm{k}_{\mathrm{e}_{1}}^{2} \tan \Lambda_{1}\right) / \pi$ holds true. Consequently, Equation (39) is rewritten as:

$$
\dot{\mathrm{V}}_{1}<-\sigma_{1,1} \mathrm{~V}_{1}+\sigma_{1,2}+\frac{1}{2} \mathrm{e}_{2}^{2}
$$

where $\sigma_{1,1}=\min \left\{\gamma_{1},\left(2 / \tau_{2}-2\right)\right\}$ and $\sigma_{1,2}=\mathrm{M}_{1}^{2} / 2$.

Considering the measurement noise and the RBF neural network estimation of aerodynamic torque (Equation (26)), the rotor dynamic response (Equation (25)) can be rewritten as:

$$
\ddot{\omega}_{\mathrm{r}}=\mathrm{g}_{1}+\mathrm{c}_{3} \theta^{* \mathrm{~T}} \mathbf{h}-\frac{\mathrm{a}_{3} \omega_{\mathrm{n}, \mathrm{N}} \beta \mathrm{T}_{\mathrm{a}, \beta}}{2 \xi_{\mathrm{N}}}-\frac{\mathrm{a}_{3} \ddot{\beta} \mathrm{T}_{\mathrm{a}, \beta}}{2 \omega_{\mathrm{n}, \mathrm{N}} \xi_{\mathrm{N}}}+\mathrm{G} \beta_{\mathrm{ref}}+\frac{\mathrm{a}_{3} \mathrm{~T}_{\mathrm{a}, \beta}}{2 \xi_{\mathrm{N}}} \mathrm{f}+\mathrm{d},
$$

where $\mathrm{g}_{1}=\mathrm{c}_{1} \omega_{\mathrm{r}}+\mathrm{c}_{2} \omega_{\mathrm{g}}+\mathrm{c}_{4} \mathrm{~T}_{\mathrm{g}}, \mathrm{d}=\mathrm{c}_{1} v_{\omega_{\mathrm{r}}}+\mathrm{c}_{2} v_{\omega_{\mathrm{g}}}+\mathrm{c}_{3} \varepsilon+\mathrm{a}_{3} \omega_{\mathrm{n}, \mathrm{N}} \mathrm{T}_{\mathrm{a}, \beta} v_{\beta} / 2 \xi_{\mathrm{N}}+$ $a_{3} T_{a, \beta} v_{\ddot{\beta}} / 2 \omega_{n, N} \xi_{N}+a_{3} \omega_{n, N} D T_{a, \beta} / 2 \xi_{N}+a_{3} \Delta T_{a, \Delta c_{p}}, \quad G=a_{3} S_{\beta_{u}} \omega_{n, N} \rho T_{a, \beta} / 2 \xi_{N}$, and $f=$ $\Delta \widetilde{\mathrm{f}}_{\mathrm{PAD}} / \omega_{\mathrm{n}, \mathrm{N}}+\mathrm{S}_{\beta_{\mathrm{u}}} \omega_{\mathrm{n}, \mathrm{N}} \Phi$. Considering the bounded achievable, $\beta, \dot{\beta}$, and $\beta_{\mathrm{u}}$, the boundedness of $\Delta \widetilde{f f A D}_{\mathrm{PAD}}, \mathrm{S}_{\beta_{\mathrm{u}}}$, and $\Phi$ are concluded. This, in turn, leads to the bondedness of the fault signal, $\mathrm{f}$, in Equation (41), i.e., $|\mathrm{f}| \leq \overline{\mathrm{f}}$, where $\overline{\mathrm{f}}$ is an unknown positive constant. Also, the first time derivative of $\mathrm{f}$ is assumed to be bounded, i.e., $|\dot{\mathrm{f}}| \leq \rho_{\mathrm{f}}$, where $\rho_{\mathrm{f}}$ is an unknown positive constant [4]. Indeed, it is assumed that the applied fault is a slowly varying function of time. Besides, the sensor noise contents are bounded, which is a reasonable assumption [2,17]. Accordingly, by considering Figure 4 and $|\varepsilon| \leq \bar{\varepsilon}$, the disturbance, $d$, is bounded as $|d| \leq \bar{D}$, where $\bar{D}$ is a positive unknown constant [5]. Finally, it is easily seen that $G$ is unknown but bounded, due to the presence of $T_{a, \beta}$.

Now, the proposed pitch angle controller is designed as:

$$
\beta_{\text {ref }}=\mathrm{N}\left(\zeta_{1}\right) v_{1}
$$

with:

$$
\begin{aligned}
& \dot{\zeta}_{1}=\mathrm{e}_{2} \sec ^{2} \Lambda_{2} v_{1}, \\
& v_{1}=g_{1} \frac{\chi_{1}}{\tau_{2}} c_{1} \hat{\theta}^{T} \mathbf{h}+\frac{a_{3} \omega_{n, N} \beta L}{2 \xi_{N}} \tanh \left(\frac{e_{2} \beta \sec ^{2} \Lambda_{2}}{\eta_{1}}\right)+\frac{a_{3} \ddot{\beta} L}{2 \omega_{n, N} \xi_{N}} \tanh \left(\frac{e_{2} \ddot{\beta} \sec ^{2} \Lambda_{2}}{\eta_{2}}\right)+ \\
& \hat{\mathrm{d}} \tanh \left(\frac{\mathrm{e}_{2} \sec ^{2} \Lambda_{2}}{\eta_{3}}\right)+\frac{\mathrm{a}_{3} \mathrm{~L} \ddot{\mathrm{f}}}{2 \xi_{\mathrm{N}}} \tanh \left(\frac{\mathrm{e}_{2} \sec ^{2} \Lambda_{2}}{\eta_{4}}\right)+\gamma_{2} \mathrm{e}_{2},
\end{aligned}
$$

associated with the adaptive laws:

$$
\begin{gathered}
\dot{\hat{\mathrm{f}}}=\frac{\mathrm{e}_{2} \mathrm{a}_{3} \mathrm{~L}}{2 \xi_{\mathrm{N}}} \sec ^{2} \Lambda_{2} \tanh \left(\frac{\mathrm{e}_{2} \sec ^{2} \Lambda_{2}}{\eta_{4}}\right)-\sigma_{\mathrm{f}} \hat{\mathrm{f}}, \\
\dot{\hat{\theta}}=\Gamma\left(\mathrm{e}_{2} \mathrm{c}_{3} \sec ^{2} \Lambda_{2} \mathrm{~h}-\sigma_{\mathrm{c}} \hat{\boldsymbol{\theta}}\right), \\
\dot{\hat{\mathrm{d}}}=\mathrm{e}_{2} \sec ^{2} \Lambda_{2} \tanh \left(\frac{\mathrm{e}_{2} \sec ^{2} \Lambda_{2}}{\eta_{3}}\right)-\sigma_{\mathrm{d}} \hat{\mathrm{d}},
\end{gathered}
$$


to estimate the fault, the RBF neural network weights and disturbance, respectively, where, $\eta_{1}, \eta_{2}$, $\eta_{3}, \eta_{4}, \gamma_{2}, \sigma_{\mathrm{f}}, \sigma_{\mathrm{c}}$, and $\sigma_{\mathrm{d}}$ are positive design parameters. Also, $\Gamma \in \mathbb{R}^{\mathrm{s}}$ is a design matrix such that $\Gamma=\Gamma^{\mathrm{T}}>0$. Accordingly, the estimation errors are defined as:

$$
\widetilde{\mathrm{f}}=\hat{\mathrm{f}}-\mathrm{f}, \widetilde{\mathrm{d}}=\hat{\mathrm{d}}-\overline{\mathrm{D}}, \widetilde{\theta}=\hat{\theta} \theta^{*}
$$

Considering the bounded applicable fault, it is practically reasonable to assume the estimation error is bounded as $|\widetilde{f}| \leq \rho_{\mathrm{f}^{\prime}}$, where $\rho_{\mathrm{f}}^{-}$is an unknown positive constant [4]. It should be noted that this bound is only used to analyze the stability of the closed-loop system. Nevertheless, this will not be used in the designed control structure, as it is assumed to be unknown. So, the actual estimation will not be required in setting up and implementing the control scheme.

Now, a Lyapunov function is selected as:

$$
\mathrm{V}_{2}=\frac{\mathrm{k}_{\mathrm{e}_{2}}^{2}}{\pi} \tan \Lambda_{2}+\frac{1}{2} \overrightarrow{\mathrm{f}}^{2}+\frac{1}{2} \widetilde{\mathrm{d}}^{2}+\frac{1}{2} \widetilde{\theta}^{\mathrm{T}} \Gamma^{-1} \widetilde{\theta}
$$

where $\Lambda_{2}=\pi \xi_{2}^{2} / 2, \xi_{2}=\mathrm{e}_{2} / \mathrm{k}_{\mathrm{e}_{2}}$ and $\mathrm{k}_{\mathrm{e}_{2}}$ is a considered constraint on $\mathrm{e}_{2}$. It is worth noting that $\mathrm{V}_{2}$ is continuous in $\Omega_{\mathrm{e}_{2}}=\left\{\mathrm{e}_{2}:-\mathrm{k}_{\mathrm{e}_{2}}<\mathrm{e}_{2}<\mathrm{k}_{\mathrm{e}_{2}}\right\} . \mathrm{V}_{2}$ is positive definite and its first term captures the BLF characteristics of the modified tracking error, $\xi_{2}$, according to Definition 2 . The time derivative of $\xi_{2}$ is obtained as:

$$
\dot{\xi}_{2}=\frac{\ddot{\omega}_{\mathrm{r}}+\frac{\chi_{2}}{\tau_{2}}}{k_{\mathrm{e}_{2}}} .
$$

The first-time derivative of Equation (46) can be obtained as:

$$
\begin{gathered}
\dot{V}_{2}=\mathrm{e}_{1}+\left(\mathrm{g}_{1}+\mathrm{c}_{1} \theta^{* \mathrm{~T}} \mathbf{h}-\frac{\mathrm{a}_{3} \omega_{\mathrm{n}, \mathrm{N}} \beta \mathrm{T}_{\mathrm{a}, \beta}}{2 \dot{\varepsilon}_{\mathrm{N}}}-\frac{\mathrm{a}_{3} \ddot{\beta} \mathrm{T}_{\mathrm{a}, \beta}}{2 \omega_{\mathrm{n}, \mathrm{N}} \dot{\xi}_{\mathrm{N}}}+\mathrm{G} \beta_{\text {ref }}+\frac{\mathrm{a}_{3} \mathrm{~T}_{\mathrm{a}, \beta}}{2 \dot{\xi}_{\mathrm{N}}} \mathrm{f}+\mathrm{d}+\frac{\mathrm{\chi}_{2}}{\tau_{2}}\right) \sec ^{2} \Lambda_{2}+ \\
\widetilde{\mathrm{f}}(\hat{\hat{\mathrm{f}}}-\dot{\mathrm{f}})+\widetilde{\mathrm{d}} \hat{\mathrm{d}}+\widetilde{\theta}^{\mathrm{T}} \Gamma^{-1} \dot{\hat{\mathrm{\theta}}} .
\end{gathered}
$$

Substituting Equations (42)-(44) into Equation (48) leads to:

$$
\dot{\mathrm{V}}_{2}=\mathrm{GN}\left(\zeta_{1}\right) \dot{\zeta}_{1}+\dot{\zeta}_{1}+\sum_{\mathrm{i}=1}^{6} \Pi_{\mathrm{i}}
$$

where:

$$
\begin{aligned}
& \Pi_{1}=-\mathrm{e}_{2} \frac{\mathrm{a}_{3} \omega_{\mathrm{n}, \mathrm{N}} \beta \mathrm{T}_{\mathrm{a}, \beta}}{2 \xi_{\mathrm{N}}} \sec ^{2} \Lambda_{2}-\mathrm{e}_{2} \frac{\mathrm{a}_{3} \omega_{\mathrm{n}, \mathrm{N}} \beta \mathrm{L}}{2 \xi_{\mathrm{N}}} \sec ^{2} \Lambda_{2} \tanh \left(\frac{\beta \mathrm{e}_{2} \sec ^{2} \Lambda_{2}}{\eta_{1}}\right), \\
& \Pi_{2}=-e_{2} \frac{a_{3} \ddot{\beta} T_{a, \beta}}{2 \omega_{n, N} \xi_{N}} \sec ^{2} \Lambda_{2}-e_{2} \frac{a_{3} \ddot{\beta} L}{2 \omega_{n, N} \xi_{N}} \sec ^{2} \Lambda_{2} \tanh \left(\frac{e_{2} \ddot{\beta} \sec ^{2} \Lambda_{2}}{\eta_{2}}\right), \\
& \Pi_{3}=\operatorname{de}_{2} \sec ^{2} \Lambda_{2}+\widetilde{d e}_{2} \sec ^{2} \Lambda_{2} \tanh \left(\frac{e_{2} \sec ^{2} \Lambda_{2}}{\eta_{3}}\right)-\sigma_{d} \hat{d} \widetilde{d}-\hat{d} \tanh \left(\frac{e_{2} \sec ^{2} \Lambda_{2}}{\eta_{3}}\right) e_{2} \sec ^{2} \Lambda_{2} \text {, } \\
& \Pi_{4}=e_{2} \frac{a_{3} T_{a, \beta}}{2 \xi_{N}} f \sec ^{2} \Lambda_{2}-\frac{e_{2} a_{3} L}{2 \xi_{N}} f \sec ^{2} \Lambda_{2} \tanh \left(\frac{e_{2} \sec ^{2} \Lambda_{2}}{\eta_{4}}\right)-\sigma_{f} \widetilde{f f}-\widetilde{f f}, \\
& \Pi_{5}=-\sigma_{\mathrm{c}} \widetilde{\boldsymbol{\theta}}^{\mathrm{T}} \hat{\boldsymbol{\theta}} \text {, and } \Pi_{6}=-\gamma_{\mathrm{c}} \mathbf{e}_{2}^{2} \sec _{2} \Lambda_{2} .
\end{aligned}
$$

Considering Definition 1 and the inequality $0 \leq\left|\mathrm{e}_{2} \| \beta\right| \sec ^{2} \Lambda_{2}$, it leads to $\left(\left|\mathrm{T}_{\mathrm{a}, \beta}\right|\left|\mathrm{e}_{2} \| \beta\right| \sec ^{2} \Lambda_{2}\right) / \mathrm{L} \leq$ $\left|e_{2} \| \beta\right| \sec ^{2} \Lambda_{2}$. Accordingly, based on Lemmas 4 and 5 , the following relations can be written:

$$
\Pi_{1} \leq \frac{a_{3} \omega_{n, N} L}{2 \xi_{N}}\left(\left|e_{2} \| \beta\right| \sec ^{2} \Lambda_{2}-e_{2} \beta \sec ^{2} \Lambda_{2} \tanh \left(\frac{e_{2} \beta \sec ^{2} \Lambda_{2}}{\eta_{1}}\right)\right) \leq \frac{a_{3} \omega_{n, N} L}{2 \xi_{N}} K \eta_{1} .
$$


Similarly, considering $\left(\left|\mathrm{T}_{\mathrm{a}, \beta}\right|\left|\mathrm{e}_{2}\right||\ddot{\beta}| \sec ^{2} \Lambda_{2}\right) / \mathrm{L} \leq\left|\mathrm{e}_{2}\right||\ddot{\beta}| \sec ^{2} \Lambda_{2}$, it leads to:

$$
\Pi_{2} \leq \frac{a_{3} L}{2 \omega_{n, N} \xi_{N}}\left(\left|e_{2}\right||\ddot{\beta}| \sec ^{2} \Lambda_{2}-e_{2} \ddot{\beta} \sec ^{2} \Lambda_{2} \tanh \left(\frac{e_{2} \ddot{\beta} \sec ^{2} \Lambda_{2}}{\eta_{2}}\right)\right) \leq \frac{a_{3} L}{2 \omega_{n, N} \xi_{N}} K \eta_{2} .
$$

Also, with the aid of Lemma 4, the following inequality is obtained:

$$
\begin{aligned}
& \Pi_{3} \leq \overline{\mathrm{D}}\left|\mathrm{e}_{2}\right| \sec ^{2} \Lambda_{2}-\overline{\mathrm{D}} \mathrm{e}_{2} \sec ^{2} \Lambda_{2} \tanh \left(\frac{\mathrm{e}_{2} \sec ^{2} \Lambda_{2}}{\eta_{3}}\right)-\sigma_{\mathrm{d}} \mathrm{d} \widetilde{\mathrm{d}} \leq \overline{\mathrm{D}} K \eta_{3}-\frac{\sigma_{\mathrm{d}}}{2} \widetilde{\mathrm{d}}^{2}+\frac{\sigma_{\mathrm{d}}}{2} \overline{\mathrm{D}}^{2}, \\
& \Pi_{4} \leq \frac{\mathrm{a}_{3} \mathrm{~L} \overline{\mathrm{f}}}{2 \xi_{\mathrm{N}}}\left(\left|\mathrm{e}_{2}\right| \sec ^{2} \Lambda_{2}-\mathrm{e}_{2} \sec ^{2} \Lambda_{2} \tanh \left(\frac{\mathrm{e}_{2} \sec ^{2} \Lambda_{2}}{\eta_{4}}\right)\right)-\frac{\sigma_{\mathrm{f}}}{2} \overrightarrow{\mathrm{f}}^{2} \frac{\sigma_{\mathrm{f}}}{2} \overrightarrow{\mathrm{f}}^{2}+\rho_{\mathrm{f}} \rho_{\overline{\mathrm{f}}} \leq-\frac{\sigma_{\mathrm{f}}}{2} \overrightarrow{\mathrm{f}}^{2}+ \\
& \frac{\mathrm{a}_{3} \mathrm{~L} \overline{\mathrm{f}}}{2 \varepsilon_{\mathrm{N}}} \mathrm{K \eta}_{4}+\frac{\sigma_{\mathrm{G}}}{2} \overline{\mathrm{f}}^{2}+\rho_{\mathrm{f}} \rho_{\mathrm{f}^{\prime}} \\
& \Pi_{5} \leq \frac{-\sigma_{c}}{2}\|\widetilde{\theta}\|^{2}+\frac{\sigma_{c}}{2}\left\|\theta^{*}\right\|^{2} \leq \frac{-\sigma_{c}}{2 \lambda_{\max }\left(\Gamma^{-1}\right)} \widetilde{\theta}^{T} \Gamma^{-1} \widetilde{\theta}+\frac{\sigma_{c}}{2}\left\|\theta^{*}\right\|^{2},
\end{aligned}
$$

where $\lambda_{\max }\left(\Gamma^{-1}\right)$ is the maximum eigenvalue of $\Gamma^{-1}$. Finally, considering Lemma 3, it leads to:

$$
\Pi_{6}<-\gamma_{2} \frac{\mathrm{k}_{\mathrm{e}_{2}}^{2}}{\pi} \tan \Lambda_{2} .
$$

Using Equations (50)-(53) in Equation (49), the following inequality is obtained:

$$
\dot{\mathrm{V}}_{2}<\mathrm{GN}\left(\zeta_{1}\right) \dot{\zeta}_{1}+\dot{\zeta}_{1}-\sigma_{2,1} \mathrm{~V}_{2}+\sigma_{2,2}
$$

where $\sigma_{2,1}=\min \left\{\gamma_{2}, \sigma_{\mathrm{f}}, \sigma_{\mathrm{d}}, \sigma_{\mathrm{c}} / \lambda_{\max }\left(\Gamma^{-1}\right)\right\}$ and $\sigma_{2,2}=\mathrm{a}_{3} \omega_{\mathrm{n}, \mathrm{N}} \mathrm{LK} \eta_{1} / 2 \xi_{\mathrm{N}}+\mathrm{a}_{3} \mathrm{LK} \eta_{2} / 2 \omega_{\mathrm{n}, \mathrm{N}} \xi_{\mathrm{N}}+$ $\overline{\mathrm{D}} \mathrm{K} \eta_{3}+\sigma_{\mathrm{d}} \overline{\mathrm{D}}^{2} / 2+\mathrm{a}_{3} \mathrm{~L} \overline{\mathrm{f}} \mathrm{K} \eta_{4} / 2 \xi_{\mathrm{N}}+\sigma_{\mathrm{f}} \overline{\mathrm{f}}^{2} / 2+\rho_{\mathrm{f}} \rho_{\overline{\mathrm{f}}}+\sigma_{\mathrm{c}}\left\|\theta^{*}\right\|^{2} / 2$. Now, the main property of the designed pitch controller is proven by Theorem 1 .

Theorem 1. Consider the wind turbine rotor dynamic model (Equation (25)), with non-smooth input saturation (Equation (10)) approximated with Equation (13), including pitch actuator bias, effectiveness loss, dynamic changes, and blade aerodynamic change. If the initial conditions $e_{i}(0) \in\left\{e_{i}:\left|e_{i}(0)\right|<k_{e_{i}}\right\}$ for $i=1,2$, by using the control inputs (Equations (42) and (43)), with the filter (Equation (30)), the virtual control (Equation (34)), the adaption laws (Equation (44)), then the following objectives are obtained: (i) All states of the closed-loop system are bounded; (ii) the constraint sets, $\Omega_{e_{i}}=\left\{e_{i}:\left|e_{i}\right|<k_{e_{i}}\right\}$, are not violated for $i=1,2$; and (iii) the tracking error, $e_{1}$, can be made small by the proper choice of the design parameters.

Proof. The multiplication of Equation (54) by $\exp \left(\sigma_{2,1} \mathrm{t}\right)$ yields:

$$
\mathrm{d}\left(\mathrm{V}_{2}(\mathrm{t}) \mathrm{e}^{\sigma_{2,1} \mathrm{t}}\right) / \mathrm{dt}<\left(\mathrm{GN}\left(\zeta_{1}\right) \dot{\zeta}_{1}+\dot{\zeta}_{1}+\sigma_{2,2}\right) \mathrm{e}^{\sigma_{2,1} \mathrm{t}}
$$

Thus, the integration of Equation (55) over $[0, t]$, becomes:

$$
\mathrm{V}_{2}(\mathrm{t})<\sigma_{2,2} / \sigma_{2,1}+\left(\mathrm{V}_{2}(0)-\sigma_{2,2} / \sigma_{2,1}\right) \mathrm{e}^{-\sigma_{2,1} \mathrm{t}}+\mathrm{e}^{-\sigma_{2,1} \mathrm{t}} \int_{0}^{\mathrm{t}}\left(\mathrm{GN}\left(\zeta_{1}\right)+1\right) \dot{\zeta}_{1} \mathrm{e}^{\sigma_{2,1} \tau} \mathrm{d} \tau .
$$

Furthermore, considering $\sigma_{2,2} / \sigma_{2,1}>0$ and $\lim _{t \rightarrow \infty} \exp \left(-\sigma_{2,1} t\right)=0$, Equation (56) is rewritten as:

$$
\mathrm{V}_{2}(\mathrm{t})<\mathrm{c}_{1,1}+\mathrm{e}^{-\sigma_{2,1} \mathrm{t}} \int_{0}^{\mathrm{t}}\left(\mathrm{GN}\left(\zeta_{1}\right)+1\right) \dot{\zeta}_{1} \mathrm{e}^{\sigma_{2,1} \tau} \mathrm{d} \tau,
$$

where $c_{1,1}=\sigma_{2,2} / \sigma_{2,1}+V_{2}(0)$. Also, $G$ satisfies the conditions in Lemma 1 . Accordingly, considering Equation (57), it can be stated that $V_{2}$ and $\zeta_{1}$ are bounded. Consequently, according to Equation (46), 
$\left(\mathrm{k}_{\mathrm{e}_{2}}^{2} \tan \Lambda_{2}\right) / \pi, \widetilde{\mathrm{f}}, \widetilde{\mathrm{d}}$ and $\widetilde{\theta}$ are bounded, which implies $\mathrm{e}_{2}$ belongs to set $\Omega_{\mathrm{e}_{2}}=\left\{\mathrm{e}_{2}:\left|\mathrm{e}_{2}\right|<\mathrm{k}_{\mathrm{e}_{2}}\right\}$ and accordingly is bounded. Then, one can obtain that:

$$
\frac{1}{2} \mathrm{e}_{2}^{2} \leq \mathrm{m}_{1,1}
$$

where $\mathrm{m}_{1,1}=0.5 \max _{\tau \in[0, t]} \mathrm{e}_{2}^{2}(\tau)$. Now, considering Equation (59), Equation (40) is rewritten as:

$$
\dot{\mathrm{V}}_{1}(\mathrm{t})<-\sigma_{1,1} \mathrm{~V}_{1}(\mathrm{t})+\mathrm{c}_{1,2}
$$

where $c_{1,2}=\sigma_{1,2}+m_{1,1}$. According to Lemma 2, $V_{1}$ is bounded and considering Equation (31), $\left(\mathrm{k}_{\mathrm{e}_{1}}^{2} \tan \Lambda_{1}\right) / \pi$ and $\chi_{2}$ are bounded, which implies $\mathrm{e}_{1}$ belongs to set $\Omega_{\mathrm{e}_{1}}=\left\{\mathrm{e}_{1}:\left|\mathrm{e}_{1}\right|<\mathrm{k}_{\mathrm{e}_{1}}\right\}$.

From the above-mentioned analysis, the objectives (i), (ii), and (iii) are achieved as follows:

(i). Consider the boundedness of $\mathrm{V}_{1}, \mathrm{~V}_{2}, \mathrm{e}_{2}$, and $\mathrm{e}_{1}$. Therefore $\omega_{\mathrm{r}}$ and $\dot{\omega}_{\mathrm{r}}$ are bounded. Now, from the boundedness of $\widetilde{f}, \widetilde{d}$, and $\widetilde{\theta}$, the boundedness of $\alpha_{1}, \zeta_{1}, v_{1}, \hat{f}, \hat{d}, \hat{\theta}$, and consequently $\beta_{\text {ref }}$ is proven.

(ii). As part of the closed-loop system analysis, it is shown that the tracking errors, $\mathrm{e}_{1}$ and $\mathrm{e}_{2}$, always stay in the sets, $\Omega_{\mathrm{e}_{1}}=\left\{\mathrm{e}_{1}:\left|\mathrm{e}_{1}\right|<\mathrm{k}_{\mathrm{e}_{1}}\right\}$ and $\Omega_{\mathrm{e}_{2}}=\left\{\mathrm{e}_{2}:\left|\mathrm{e}_{2}\right|<\mathrm{k}_{\mathrm{e}_{2}}\right\}$, respectively.

(iii). Multiplying both sides of Equation (59) by $\exp \left(\sigma_{1,1} \mathrm{t}\right)$ yields:

$$
\mathrm{d}\left(\mathrm{V}_{1}(\mathrm{t}) \mathrm{e}^{\sigma_{1,1} \mathrm{t}}\right) / \mathrm{dt}<\mathrm{c}_{1,2} \mathrm{e}^{\sigma_{1,1} \mathrm{t}}
$$

Thus, the integration of Equation (60) over $[0, t]$, becomes:

$$
\mathrm{V}_{1}(\mathrm{t})<\mathfrak{D}
$$

where $\mathfrak{D}=\left(\mathrm{V}_{1}(0)-\mathrm{c}_{1,2} / \sigma_{1,1}\right) \exp \left(-\sigma_{1,1} \mathrm{t}\right)+\mathrm{c}_{1,2} / \sigma_{1,1}$. From the definition of $\mathrm{V}_{1}$, it can be shown that:

$$
\left|\mathrm{e}_{1}\right|<O
$$

where $O=\mathrm{k}_{\mathrm{e}_{2}} \sqrt{2 \tan ^{-1}\left(\pi \mathfrak{D} / \mathrm{k}_{\mathrm{e}_{1}}^{2}\right) / \pi}$. If $\mathrm{V}_{1}(0)=\mathrm{c}_{1,2} / \sigma_{1,1}$, then it holds that $\left|\mathrm{e}_{1}\right|<$ $\mathrm{k}_{\mathrm{e}_{1}} \sqrt{2 \tan ^{-1}\left(\pi \mathrm{c}_{1,2} / \mathrm{k}_{\mathrm{e}_{1}}^{2} \sigma_{1,1}\right) / \pi}$. If $\mathrm{V}_{1}(0) \neq \mathrm{c}_{1,2} / \sigma_{1,1}$, it can be concluded that given any $O>$ $\mathrm{k}_{\mathrm{e}_{1}} \sqrt{2 \tan ^{-1}\left(\pi \mathrm{c}_{1,2} / \mathrm{k}_{\mathrm{e}_{1}}^{2} \sigma_{1,1}\right) / \pi}$, there exists $\mathrm{T}$, such that for any $\mathrm{t}>\mathrm{T}$, it has $\left|\mathrm{e}_{1}\right|<O$. As $\mathrm{t} \rightarrow \infty$, $\left|\mathrm{e}_{1}\right|<\mathrm{k}_{\mathrm{e}_{1}} \sqrt{2 \tan ^{-1}\left(\pi \mathrm{c}_{1,2} / \mathrm{k}_{\mathrm{e}_{1}}^{2} \sigma_{1,1}\right) / \pi}$, which implies that $\mathrm{e}_{1}$ can be made arbitrarily small by selecting the design parameters appropriately.

Considering Definition 3, and the objectives (i), (ii), and (iii), it is guaranteed that the closed-loop system is UUB. This completes the proof.

Remark 2. In Theorem 1, the objective (i) implies that the wind turbine equipped with the proposed pitch angle controller is stable. The objective (ii) states the constrained rotor speed and acceleration are guaranteed. Accordingly, the generator speed and generated power are retained in the given bounds. Considering Section 3, then the efficient power regulation requirements are met, satisfying the power grid demand. In this manner, both rotor overspeeding and mechanical brake engagement are avoided. The objective (iii) represents the expert's knowledge in the implementation stage of the proposed controller to satisfactorily make the tracking error small. These objectives are satisfied in the presence of pitch actuator faults, dynamic change, saturation, and blade aerodynamic characteristic change. 


\section{Fault Identification Scheme}

In this section, a scheme is given to identify the pitch actuator fault, including the pitch bias, $\Phi$, effectiveness loss, $\rho$, dynamic change, $\Delta \widetilde{\mathrm{f}}_{\mathrm{PAD}}$, and aerodynamic characteristic change, $\Delta \mathrm{T}_{\mathrm{a}, \Delta \mathrm{C}_{\mathrm{p}}}$. To this aim, the auxiliary signals are calculated and compared to the estimated fault, $\hat{f}$, to identify the case of the dynamic change. Considering Table 2 and the definition of $\Delta \widetilde{\mathrm{f}}_{\mathrm{PAD}}$ in Equation (17), the auxiliary signals are computed as follows:

$$
\begin{gathered}
\mathrm{f}_{\text {auxiliary,fault free }}=0 \Delta\left(\widetilde{\omega}_{\mathrm{n}}^{2}\right) \beta_{\mathrm{s}}-0 \Delta\left(\widetilde{\omega}_{\mathrm{n}} \widetilde{\xi}\right) \dot{\beta}_{\mathrm{s}}+0 \Delta\left(\widetilde{\omega}_{\mathrm{n}}^{2}\right) \beta_{\text {ref }}=0, \\
\mathrm{f}_{\text {auxiliary,pump wear }}=-0.6316 \Delta\left(\widetilde{\omega}_{\mathrm{n}}^{2}\right) \beta_{\mathrm{s}}-0.59376 \Delta\left(\widetilde{\omega}_{\mathrm{n}} \widetilde{\xi}\right) \dot{\beta}_{\mathrm{s}}+0.6316 \Delta\left(\widetilde{\omega}_{\mathrm{n}}^{2}\right) \beta_{\text {ref }}, \\
\mathrm{f}_{\text {auxiliary,hydraulic leak }}=-\Delta\left(\widetilde{\omega}_{\mathrm{n}}^{2}\right) \beta_{\mathrm{s}}-1.75706 \Delta\left(\widetilde{\omega}_{\mathrm{n}} \widetilde{\xi}\right) \dot{\beta}_{\mathrm{s}}+\Delta\left(\widetilde{\omega}_{\mathrm{n}}^{2}\right) \beta_{\text {ref }}, \\
\mathrm{f}_{\text {auxiliary,high air }}=-0.81083 \Delta\left(\widetilde{\omega}_{\mathrm{n}}^{2}\right) \beta_{\mathrm{s}}-2 \Delta\left(\widetilde{\omega}_{\mathrm{n}} \widetilde{\xi}\right) \dot{\beta}_{\mathrm{s}}+0.81083 \Delta\left(\widetilde{\omega}_{\mathrm{n}}^{2}\right) \beta_{\text {ref }},
\end{gathered}
$$

where in $f_{\text {auxiliary, }, X}$, the auxiliary signal is calculated for the fault case, $X$, which includes fault free, pump wear, hydraulic leakage, or high air. In order to finalize the pitch actuator fault identification scheme, first, the dynamic change case is considered, assuming no pitch actuator bias. Considering $\mathrm{f}=\Delta \widetilde{\mathrm{f}}_{\mathrm{PAD}} / \omega_{\mathrm{n}, \mathrm{N}}+\mathrm{S}_{\beta_{\mathrm{u}}} \omega_{\mathrm{n}, \mathrm{N}} \Phi$, in the absence of $\Phi$, it can be obtained that $\mathrm{f}=\Delta \widetilde{\mathrm{f}}_{\mathrm{PAD}} / \omega_{\mathrm{n}, \mathrm{N}}$. So, using the auxiliary signals, $\mathrm{f}_{\text {auxiliary, }} \mathrm{X}$, reported in Equation (63), the most similar one to $\hat{\mathrm{f}}$ is identified as the dynamic change case. Therefore, similarity indices are needed, which enhance the fault identification task. The indices adopted in this paper are the root mean squared error (RMSE) and variance accounted for (VAF), defined as follows:

$$
\operatorname{RMSE}_{X}=\sqrt{\frac{1}{\mathrm{~T}} \int_{0}^{\mathrm{T}_{\text {exe }}}\left(\mathrm{f}_{\text {auxiliary },} \mathrm{X}-\hat{\mathrm{f}}\right)^{2} \mathrm{dt}}, \operatorname{VAF}_{X}=\left(1-\frac{\operatorname{var}\left(\mathrm{f}_{\text {auxiliary },} \mathrm{X}-\hat{\mathrm{f}}\right)}{\operatorname{var}\left(\mathrm{f}_{\text {auxiliary },} \mathrm{X}\right)}\right) \times 100 \%,
$$

where $\mathrm{T}_{\text {exe }}$ is the given operation period of the wind turbine. In the ideal fault identification case, the RMSE and VAF indices are zero and 100\%, respectively. Accordingly, the dynamic change of $X$ with the RMSE and VAF indices close to zero and $100 \%$, respectively, is selected as the corresponding dynamic change case, which is indicated as $\hat{X}$. The pitch bias, $\Phi$, is considered as an added constant on f. So, having pitch bias occur with the dynamic change, the RMSE index only deviates significantly from zero. However, the VAF index still indicates the correct dynamic change properly. Now, after the identification of $\hat{X}$, the pitch actuator bias is estimated. Considering $f=f_{\text {auxiliary, } \hat{X}} / \omega_{n, N}+S_{\beta_{u}} \omega_{n, N} \Phi$, where $\mathrm{f}_{\text {auxiliary, }, \hat{\mathrm{X}}}$ is the calculated auxiliary signal using Equation (63) for the identified dynamic change, $\hat{X}$, the estimation of pitch actuator bias, $\hat{\Phi}$, is computed as follows:

$$
\hat{\Phi}=\frac{\omega_{n, N} \hat{f}-f_{\text {auxiliary, }, \hat{x}}}{S_{\beta_{u}} \omega_{n, N}{ }^{2}} .
$$

Finally, if neither the dynamic change case nor pitch actuator bias are identified, and meanwhile, the fault-free case is not identified, then it can be concluded that the faulty case is either pitch actuator effectiveness loss or aerodynamic characteristic change. Considering Equation (41), it is clear that the aerodynamic characteristic change is considered as an additive disturbance, and attenuated by the proposed controller. On the other hand, the effectiveness loss is contributing in the control gain, i.e., G. So, the estimated fault, $\hat{\mathrm{f}}$, is affected by the effectiveness loss and is insensitive to the aerodynamic characteristic change. Accordingly, the given period is considered, in which no pitch actuator dynamic change, bias, or fault-free cases are identified. Then, if $\hat{f}$ considerably deviates from zero, this leads to the identification of the effectiveness loss. Otherwise, the aerodynamic characteristic change is identified. Therefore, the fault isolation task is accomplished. It should be mentioned that this fault identification scheme is robust against the disturbance, $d$, in Equation (41), as its effect is guaranteed to be attenuated using the proposed controller. 


\section{Numerical Evaluation and Comparison}

In this section, numerical simulations are conducted to evaluate the features of the controller (Equation (42)). Moreover, the available industrial PID controller is briefly introduced, for comparison with the proposed controller performance. Suitable numerical metrics are introduced to quantify and compare the performance of the proposed and PID controllers.

\subsection{Industrial Baseline PID Controller}

The most commonly adopted industrial controller for power regulation of wind turbines in full load operation is the PID controller, due to its simplified implementation and effectiveness [4]. The PID controller is thus used to regulate the pitch angle based on the generator speed tracking error, $\mathrm{e}_{\mathrm{g}}$ defined as:

$$
e_{g}(t)=\omega_{g, s}(t)-\omega_{g, N}
$$

Accordingly, the PID controller, used for tracking the blade pitch angle given the reference pitch angle, has the form $[4,7]$ :

$$
\beta_{\text {ref }}(t)=K_{P} e_{g}(t)+K_{I} \int_{0}^{t} e_{g}(\tau) d \tau+K_{D} \dot{e}_{g}(t),
$$

where $\mathrm{K}_{\mathrm{P}}, \mathrm{K}_{\mathrm{I}}$, and $\mathrm{K}_{\mathrm{D}}$ are the proportional, integral, and derivative gains of the controller, respectively, to be set via traditional methods, in order to guarantee system stability as well as satisfying performance. $\mathrm{K}_{\mathrm{P}}, \mathrm{K}_{\mathrm{I}}$, and $\mathrm{K}_{\mathrm{D}}$ are mostly chosen as constant gains for the whole operational region, although some works proposed the use of different gains for each operating condition of the plant [7]. The values of the PID gains here settled as $K_{P}=1, K_{I}=4$, and $K_{D}=0[4,26]$.

In the structure of the industrial controller (Equation (67)), the sensor noise, $\omega_{\mathrm{g}, \mathrm{s}}$, is not necessarily attenuated and may be amplified, even if a filter is used to remove noise content [7]. Also, any possible loss of effectiveness, $\rho(t)$, and blade aerodynamic characteristic change, $\Delta \mathrm{T}_{\mathrm{a}, \Delta \mathrm{C}_{\mathrm{p}}}$, are not analytically attenuated with this solution. Moreover, this controller does not guarantee that any pitch actuator bias, $\Phi(\mathrm{t})$, and dynamic change, $\Delta \widetilde{\mathrm{f}}_{\mathrm{PAD}}$, is correctly managed. These remarks will help to highlight the advantages of the proposed controller compared to the PID controller, which are analyzed by means of a simulated example in the next section.

\subsection{Performance Metrics}

The comparative numerical performance metrics are defined in this section. The difference between the generator speed and the nominal one is considered as the first metric, defined as:

$$
\mathrm{C} 1=\int_{0}^{\mathrm{T}_{\mathrm{exe}}}\left(\omega_{\mathrm{g}}(\tau)-\omega_{\mathrm{g}, \mathrm{N}}\right)^{2} \mathrm{~d} \tau
$$

where $T_{\text {exe }}$ is the given operation period of the wind turbine. Similarly, the difference between the generated power and the nominal one is considered as the second metric, defined as:

$$
\mathrm{C} 2=\int_{0}^{\mathrm{T}_{\mathrm{exe}}}\left(\mathrm{P}_{\mathrm{g}}(\tau)-\mathrm{P}_{\mathrm{g}, \mathrm{N}}\right)^{2} \mathrm{~d} \tau
$$

Obviously, it is desirable to keep $\mathrm{C} 1$ and $\mathrm{C} 2$ as close to zero as possible. The maximum power deviation from nominal is calculated as:

$$
\mathrm{C} 3=\max \left(\left|P_{g}(t)-P_{g, N}\right|\right) .
$$

C3 indicates the instantaneous power deviation from the nominal, which may cause a sudden break down. In contrast, C2 accumulates all power deviation, which may lead to gradual failure. 
So, it is expected that C3 never violates the settled constraint. Also, the drive train torsion angle is calculated as:

$$
\mathrm{C} 4=\int_{0}^{\mathrm{T} \text { exe }} \dot{\theta}_{\Delta}(\tau)^{2} \mathrm{~d} \tau
$$

Which represents the applied drive train torsion stress due to variation in aerodynamic torque, as a result of pitch angle variation. It is desirable that the proposed controller maintains the value of C4 near the one provided by the PID regulator, which is accepted in industrial practice. Finally, in order to evaluate limited variations of $\beta, \mathrm{C} 5$ and $\mathrm{C} 6$ are defined as:

$$
\mathrm{C} 5=\max (|\beta(\mathrm{t})|), \mathrm{C} 6=\max (|\dot{\beta}(\mathrm{t})|) .
$$

\subsection{Simulation Results}

In this section, the numerical simulations are reported to evaluate the performance of the proposed controller (Equation (42)), both in fault-free and faulty situations. Also, a comparison is made to the industrial PID controller (Equation (67)) to illustrate the effectiveness of the proposed controller, considering suitable numerical metrics. It should be noted that different fault scenarios, including single and simultaneous occurrences, and wind speed variations are introduced to investigate the robustness of the proposed controller.

The parameter values of the proposed controller are summarized here. The constraints on the rotor speed and its time derivative are selected as: $\mathrm{k}_{\mathrm{e}_{1}}=0.02 \mathrm{rad} / \mathrm{s}, \mathrm{k}_{\mathrm{e}_{2}}=0.04 \mathrm{rad} / \mathrm{s}^{2}$. With these values, the inequalities, $\left|\omega_{\mathrm{r}}-\omega_{\mathrm{r}, \mathrm{N}}\right| \leq 0.02 \mathrm{rad} / \mathrm{s}$ and $\left|\dot{\omega}_{\mathrm{r}}\right| \leq 0.04 \mathrm{rad} / \mathrm{s}^{2}$, are satisfied. Consequently, considering the operational mode, the constraints on the generator shaft speed and generated power are $\left|\omega_{\mathrm{g}}-\omega_{\mathrm{g}, \mathrm{N}}\right| \leq 1.9 \mathrm{rad} / \mathrm{s}$ and $\left|\mathrm{P}_{\mathrm{g}}-\mathrm{P}_{\mathrm{g}, \mathrm{N}}\right| \leq 0.056 \mathrm{MW}$. As it is clearly highlighted in Equation (42), a Nussbaum-type function is needed. In this paper, the Nussbaum-type function, $\mathrm{N}\left(\zeta_{1}\right)=\zeta_{1}^{2} \cos \left(\zeta_{1}\right)$, is used, which fulfils Definition 1. The RBF neural network structure has $s=10$. Also, the centres and width of the RBF neural network are selected as:

$$
\vartheta=\left[\begin{array}{cccccccccc}
30,907 & 31,207 & 31,507 & 31,807 & 32107 & 32,407 & 32,707 & 33,007 & 33,307 & 33,607 \\
90 & 110 & 120 & 140 & 162.5 & 180 & 190 & 210 & 220 & 230 \\
-2 & 1.5 & 5.11 & 8.66 & 12.22 & 15.77 & 19.33 & 22.88 & 26.44 & 30
\end{array}\right],
$$

and $\varphi_{\mathrm{c}}=10 \mathrm{ones}(10,1)$, respectively. The other control parameters values are selected as: $\tau_{2}=0.1$, $\gamma_{1}=10, \gamma_{2}=5, \eta_{1}=1, \eta_{2}=1, \eta_{3}=1, \eta_{4}=1, \sigma_{\mathrm{f}}=1, \sigma_{\mathrm{c}}=1, \sigma_{\mathrm{d}}=5, \mathrm{~L}=700000$, and $\Gamma=\mathrm{I}_{10 \times 10}$.

\subsection{Fault-Free Situation}

Firstly, the performance of the proposed controller is analyzed for a simulation time of 1500 (s). Fault-free conditions are also considered, with wind speed with mean of $19.84(\mathrm{~m} / \mathrm{s})$ and standard deviation of $1.94(\mathrm{~m} / \mathrm{s})$, as shown in Figure 5. The design should lead to the following properties: (i) The considered constraints are not violated, (ii) the pitch angle saturation is smoothly avoided, and (iii) the performance is improved compared to the conventional PID controller.

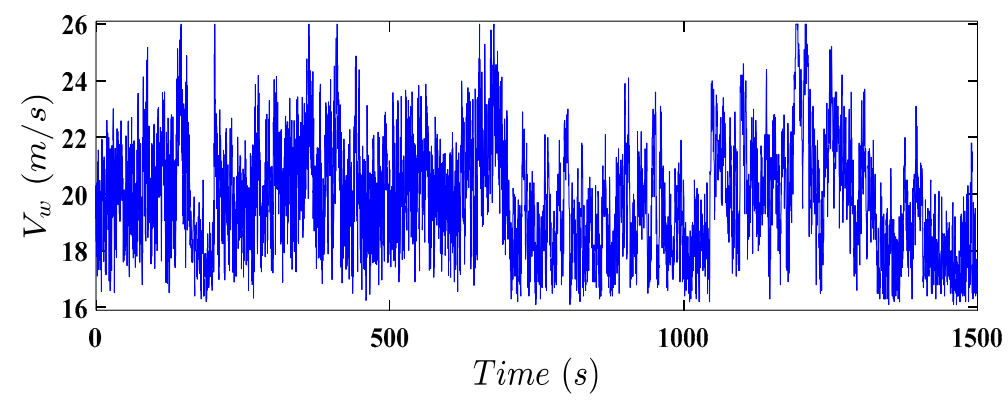

Figure 5. Free wind speed profile. 
The corresponding rotor speed, rotor acceleration, generator speed, and generated power, using the proposed controller, are shown in Figures 6-9, respectively. It can be verified that the considered constraints are not violated. On the other hand, with the same wind sequence, the PID controller results are given in Figures 6-9. The PID controller is not able to keep the corresponding outputs within the considered constraints, in the presence of the wind speed variation. Moreover, the obtained reference pitch angle using both controllers are compared in Figure 10, in which it is shown that the PID controller leads to pitch actuator saturation. In contrast, the proposed controller has smoothly avoided saturation. It should be noted that as the proposed controller maintains the rotor speed within the constraints, despite the high wind speed variation, faster pitch angle variations are generated. As mentioned in Section 3, the proposed controller is designed on the desired trajectory of the wind turbine, for which the drive train torsion angle is reduced. In order to analyze this issue, the induced drive train torsion angle using the proposed and PID controllers is depicted in Figure 11. It is shown that the induced drive train torsion angle using the proposed controller has values close to the ones achieved via the PID controller. This implies that the proposed controller has not considerably increased drive train torsion and, consequently, stress, despite the wind speed variation and more accurate nominal power tracking. The uncertain aerodynamic torque estimation is shown in Figure 12, in which the actual aerodynamic torque is reported to evaluate the estimation efficiency. It is highlighted that the aerodynamic torque is estimated quite accurately, and has been kept around the nominal one, the same as the actual aerodynamic torque. Finally, to accurately compare the results, the performance metrics using both controllers are summarized in Table 3 . It can be noted that the performance metrics, C1, C2, and $\mathrm{C} 3$, have been considerably reduced by using the proposed controller. These results correspond to Figures 6, 8 and 9. Also, the metric $\mathrm{C} 4$ shows the same induced drive train torsion angle rate, as illustrated in Figure 11. The metric C5 shows the advantage of using the smooth pitch angle saturation, as depicted in Figure 10. As remarked above, the accurate nominal power tracking needs higher pitch angle change, in the presence of high wind speed variation. This aspect can be verified considering the index $\mathrm{C} 6$. So, it can be concluded that the proposed controller improves the wind turbine performance in the fault-free case compared to the industrial PID controller.

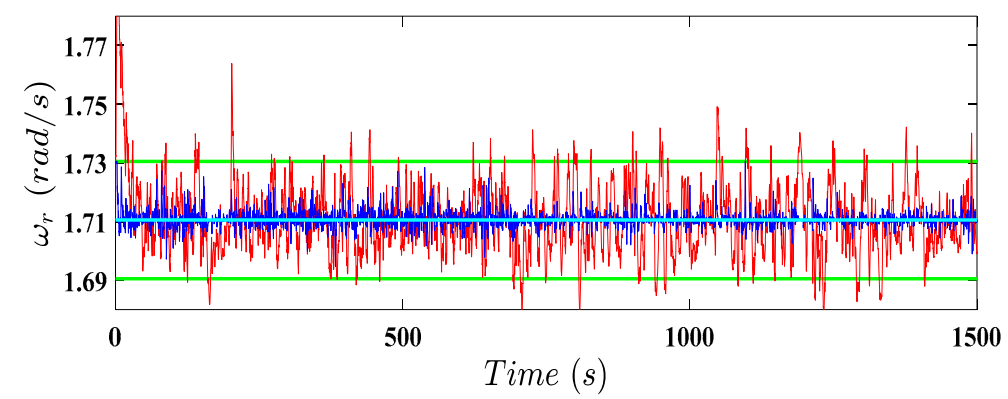

Figure 6. Rotor speed using the proposed controller (dark blue line), PID controller (red line), nominal rotor speed (light blue line), and constraints (green line), in the fault-free situation.

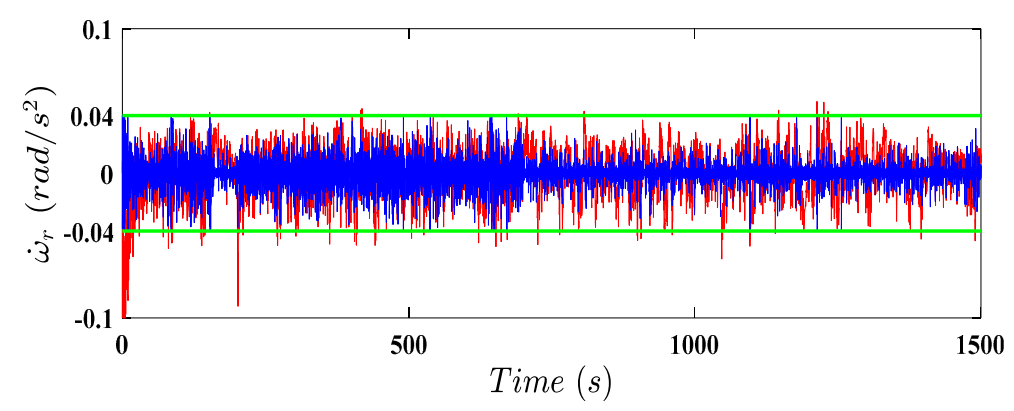

Figure 7. Rotor acceleration using the proposed controller (dark blue line), PID controller (red line), and constraints (green line), in the fault-free situation. 


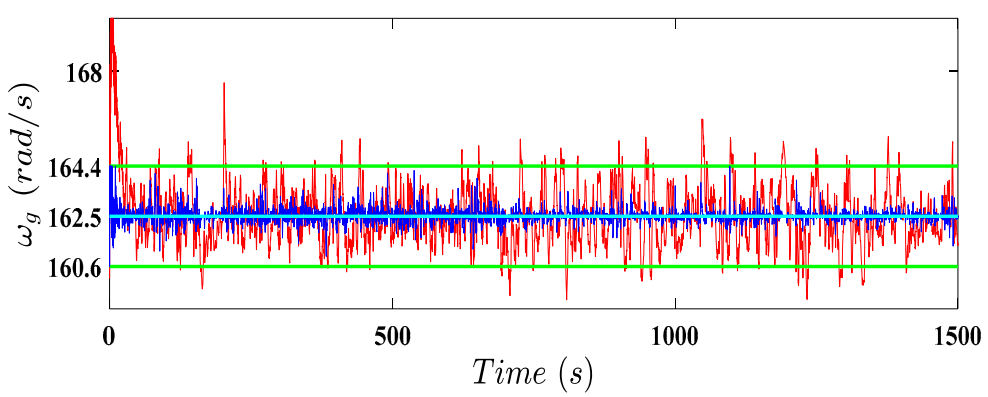

Figure 8. Generator speed using the proposed controller (dark blue line), PID controller (red line), nominal generator speed (light blue line), and constraints (green line), in the fault-free situation.

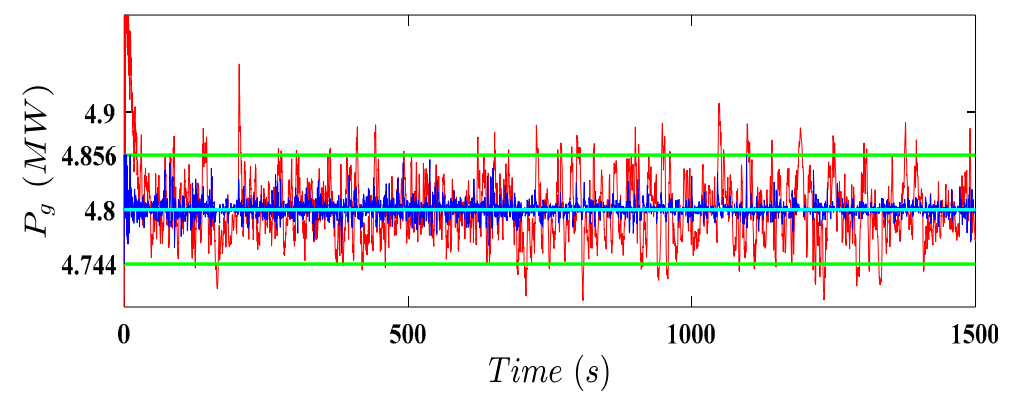

Figure 9. Generated power using the proposed controller (dark blue line), PID controller (red line), nominal power (light blue line), and constraints (green line), in the fault-free situation.

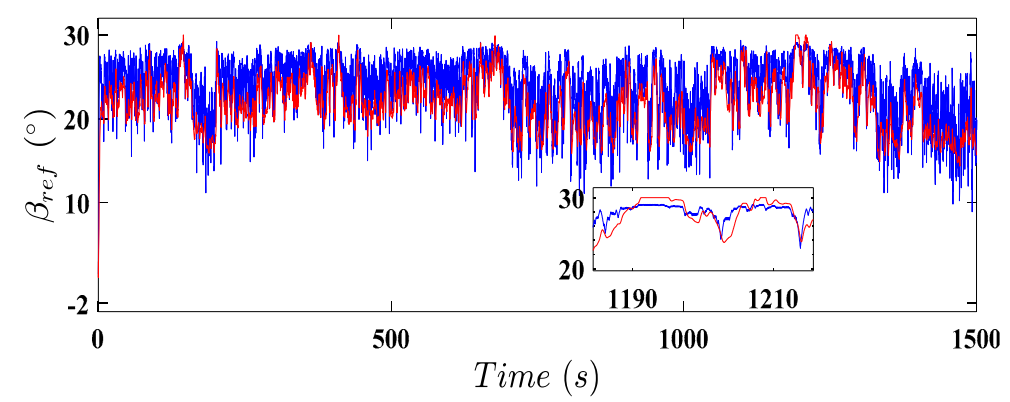

Figure 10. Reference pitch angle using the proposed controller (dark blue line) and PID controller (red line), in the fault-free situation.

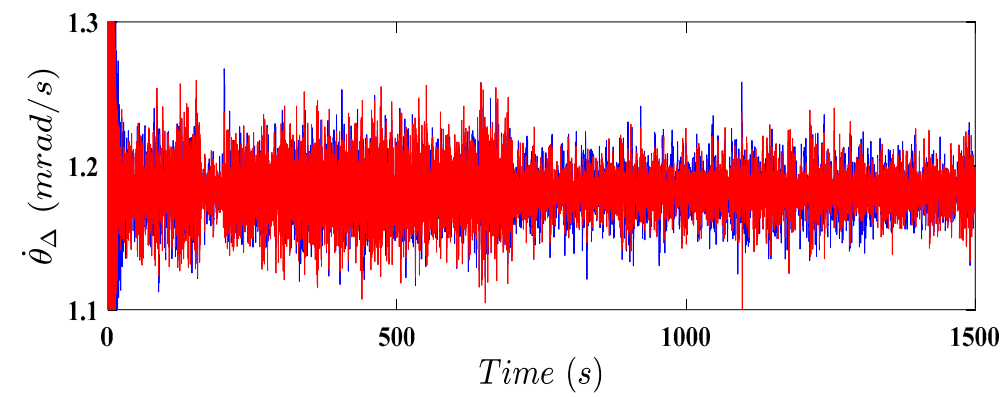

Figure 11. Induced drive train torsion angle rate using the proposed controller (dark blue line) and PID controller (red line), in the fault-free situation. 


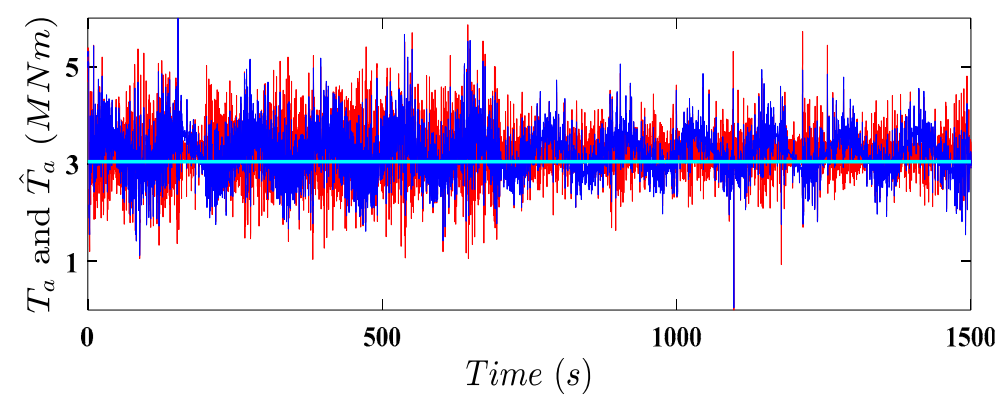

Figure 12. Actual aerodynamic torque (red line), estimated one (dark blue line), and nominal one (light blue line).

Table 3. Performance metrics in the fault-free situation.

\begin{tabular}{cccc}
\hline Performance Metrics & Proposed Controller & PID Controller & Unit \\
\hline C1 & $\mathbf{1 3 8 . 9}$ & 2266 & $\mathrm{rad}^{2} / \mathrm{s}$ \\
C2 & $\mathbf{4 0 0 . 7}$ & 2256 & $\mathrm{GW}^{2} \mathrm{~s}$ \\
C3 & $\mathbf{0 . 0 5 6}$ & 0.2937 & $\mathrm{MW}$ \\
C4 & $\mathbf{0 . 0 0 1 3 3 1}$ & 0.001416 & $\mathrm{rad}^{2} / \mathrm{s}$ \\
C5 & $\mathbf{2 9 . 3 7}$ & 30 & $\circ$ \\
C6 & 10 & $\mathbf{9 . 7 9}$ & $\circ / \mathrm{s}$ \\
\hline
\end{tabular}

\subsection{Faulty Situation}

The section evaluates the fault tolerance capabilities of the proposed controller in the presence of faults. It is expected that the mentioned constraints are not violated, whilst the fault effects are attenuated. Also, the estimated faults are analyzed with respect to the indices described in Equation (64). The results using the PID controller are also reported to study the effect of each fault as well as to highlight the benefit of the proposed controller. The considered fault scenario is defined in Table 4 . The occurrence of single faults is considered, in order to accurately study their individual effects, as highlighted in Table 4. The same wind speed sequence shown in Figure 5 is considered here. Figures 13-16 illustrate the rotor speed, rotor acceleration, generator speed, and generated power with respect to the corresponding constraints, respectively, using both the proposed and PID controllers. Compared to Figures 6-9, it is obvious that the PID controller performances are degraded, while the proposed controller is able the attenuate the fault effects and maintain the considered outputs within the corresponding constraints. The designed reference pitch angle values using both controllers are compared in Figure 17. It highlights that the simple PID controller has led to pitch actuator saturation while saturation is smoothly avoided using the proposed controller. Moreover, it is worth noting that as the proposed controller is trying to counteract the pitch actuator dynamic change, the dynamic change has reduced the speed of the pitch actuator. Accordingly, it has led to slightly higher pitch angle variations compared to the fault-free case, during the dynamic change periods. Consequently, the drive train torsion angle induced by the proposed controller was increased, as illustrated in Figure 18. In order to analyze the changes of all variables, $X$, due to the fault effect with respect to the fault-free case, the following relation is defined:

$$
\delta \mathrm{X}=\mathrm{X}_{\mathrm{ff}}-\mathrm{X}_{\mathrm{fa}},
$$

where $\delta \mathrm{X}$ is the change in the considered variable $\mathrm{X}, \mathrm{X}_{\mathrm{ff}}$ is its fault-free value, and $\mathrm{X}_{\mathrm{fa}}$ represents the corresponding value in the faulty situation. In Figures $19-21, \delta \mathrm{P}_{\mathrm{g}}, \delta \omega_{\mathrm{g}}$, and $\delta \omega_{\mathrm{r}}$, are illustrated, respectively, for the proposed and PID controllers. It is shown that the pitch actuator bias and the effectiveness loss have led to considerable limitations of the achievable PID controller performance. However, these performance degradations are significantly attenuated using the proposed controller. Also, the effect of the considered blade aerodynamic change, i.e., $\Delta \mathrm{T}_{\mathrm{a}, \Delta \mathrm{C}_{\mathrm{p}}}=5 \%$, has led to smaller variations. It should be noted that the hydraulic leak has notable effects in the performance degradation. 
To accurately study the effect of faults on the pitch actuator response, $\delta \beta$ is depicted in Figure 22 . Evidently, changes in the pitch actuator dynamic have been considerably attenuated using the proposed controller while the slower pitch actuator leads to worse performance with the PID controller. Also, the effect of pitch actuator bias is completely removed, since its effect is compensated by using the estimation of the bias itself. The situation is even worse when the PID controller is exploited. The same result is obtained considering the effectiveness loss fault. In the case of blade aerodynamic change, both controllers have led to the same trend in $\delta \beta$ while the variation using the PID controller is significantly higher. However, the fault is removed after 1300 (s), whilst its effect reduces the PID controller performance. Finally, to quantitatively compare the performance of the controllers, the values of the performance indices are summarized in Table 5. It is worth noting that the achieved performance of the proposed controller in the presence of faults are similar to the fault-free conditions. This represents the main point of the fault-tolerant control design.

Table 4. First fault scenario.

\begin{tabular}{ccc}
\hline Fault Type & Fault Effect & Fault Period \\
\hline Pitch actuator pump wear & $\alpha_{\mathrm{f}_{1}}=0.6316, \alpha_{\mathrm{f}_{2}}=0.29688$ & $200(\mathrm{~s}) \leq \mathrm{t} \leq 300(\mathrm{~s})$ \\
Pitch actuator hydraulic leak & $\alpha_{\mathrm{f}_{1}}=1, \alpha_{\mathrm{f}_{2}}=0.87853$ & $400(\mathrm{~s}) \leq \mathrm{t} \leq 500(\mathrm{~s})$ \\
Pitch angle bias & $\Phi=5^{\circ}$ & $600(\mathrm{~s}) \leq \mathrm{t} \leq 700(\mathrm{~s})$ \\
Pitch actuator high air & $\alpha_{\mathrm{f}_{1}}=0.81083, \alpha_{\mathrm{f}_{2}}=1$ & $800(\mathrm{~s}) \leq \mathrm{t} \leq 900(\mathrm{~s})$ \\
Pitch actuator effectiveness loss & $\rho=0.7$ & $1000(\mathrm{~s}) \leq \mathrm{t} \leq 1100(\mathrm{~s})$ \\
Aerodynamic characteristic change & $\Delta \mathrm{T}_{\mathrm{a}, \Delta \mathrm{C}_{\mathrm{p}}}=5 \%$ & $1200(\mathrm{~s}) \leq \mathrm{t} \leq 1300(\mathrm{~s})$ \\
\hline
\end{tabular}

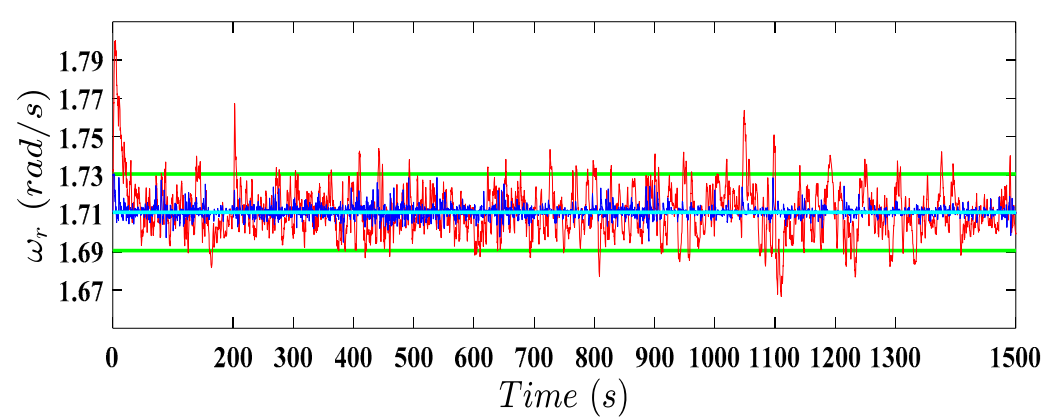

Figure 13. Rotor speed using the proposed controller (dark blue line), PID controller (red line), nominal rotor speed (light blue line), and constraints (green line), with the first fault scenario.

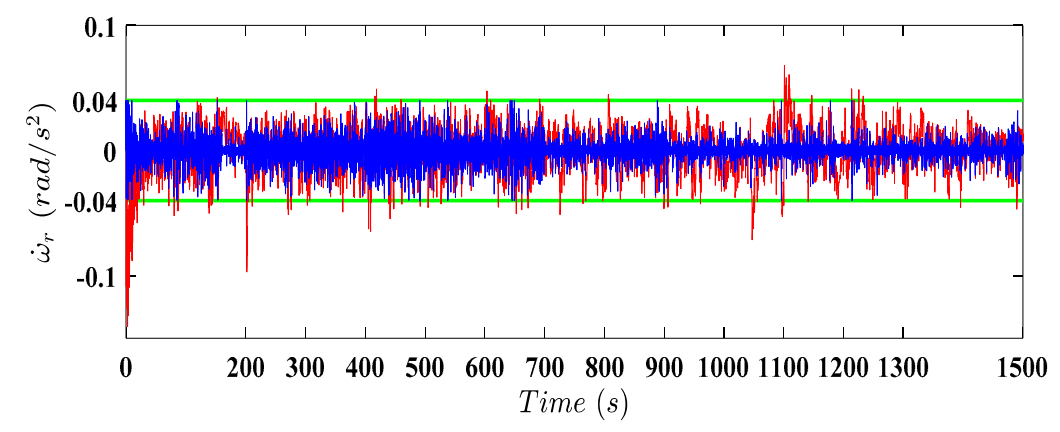

Figure 14. Rotor acceleration using the proposed controller (dark blue line), PID controller (red line), and constraints (green line), with the first fault scenario. 


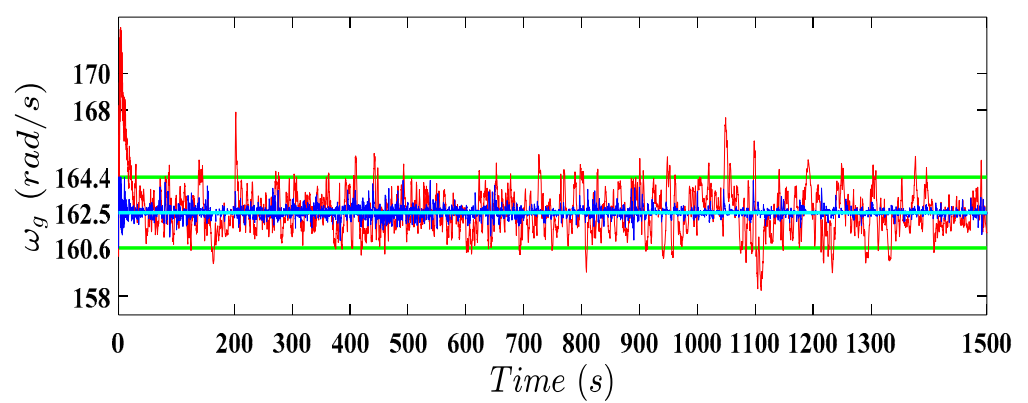

Figure 15. Generator speed using the proposed controller (dark blue line), PID controller (red line), nominal generator speed (light blue line), and constraints (green line), with the first fault scenario.

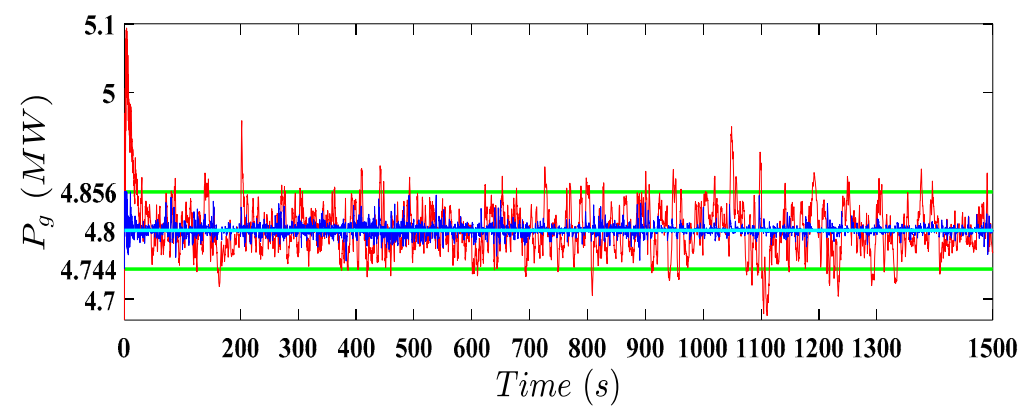

Figure 16. Generated power using the proposed controller (dark blue line), PID controller (red line), nominal power (light blue line), and constraints (green line), with the first fault scenario.

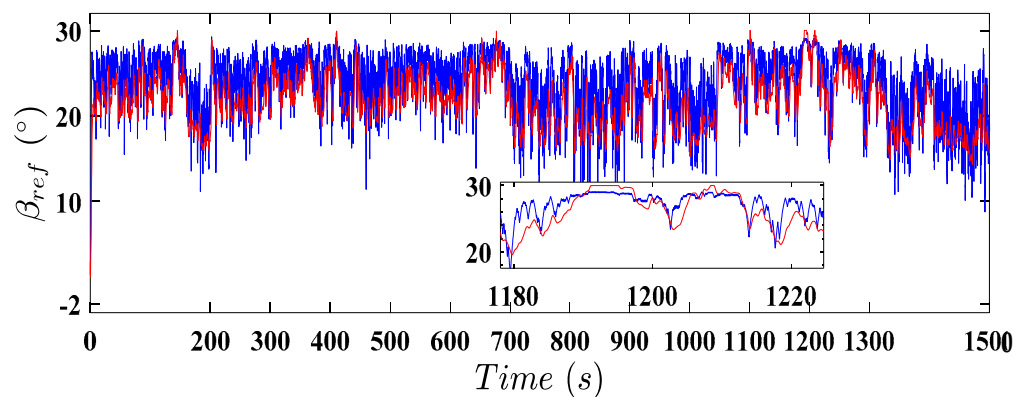

Figure 17. Reference pitch angle using the proposed controller (dark blue line) and PID controller (red line), with the first fault scenario.

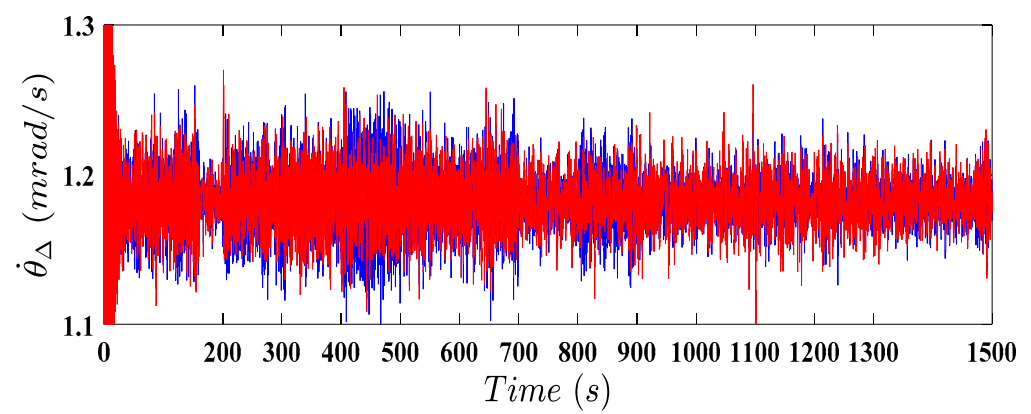

Figure 18. Induced drive train torsion angle rate using the proposed controller (dark blue line) and PID controller (red line), with the first fault scenario. 


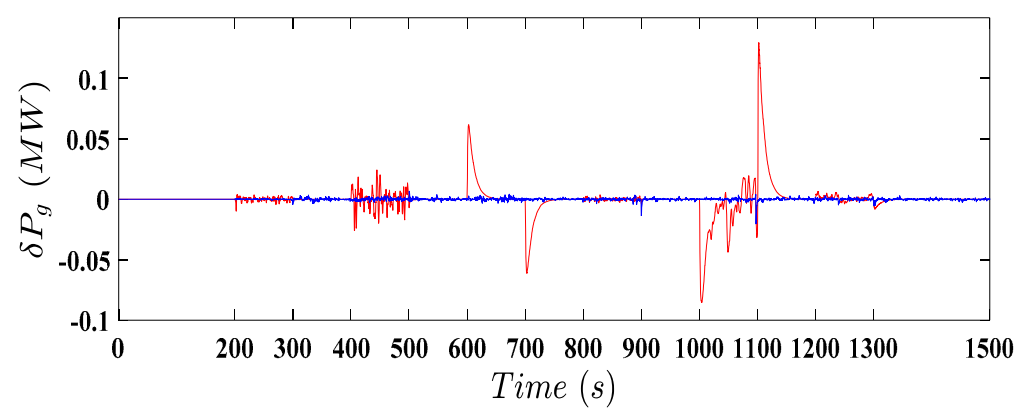

Figure 19. $\delta \mathrm{P}_{\mathrm{g}}$ using the proposed controller (dark blue line) and PID controller (red line), with the first fault scenario.

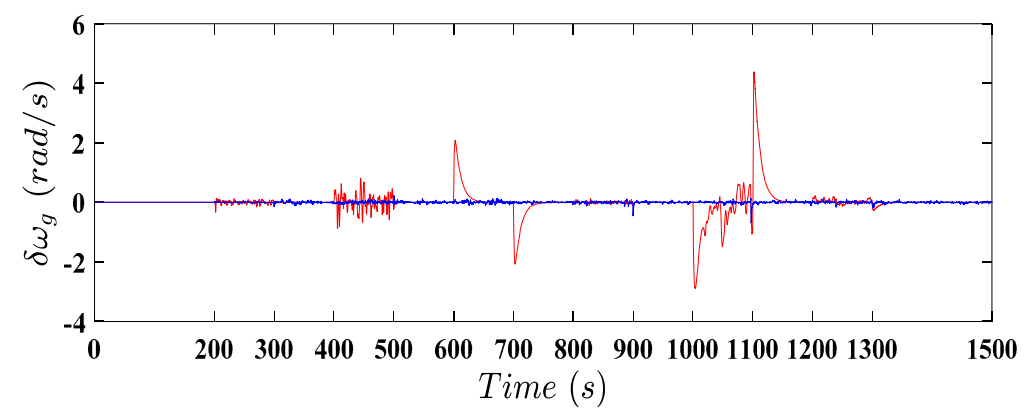

Figure 20. $\delta \omega_{\mathrm{g}}$ using the proposed controller (dark blue line) and PID controller (red line), with the first fault scenario.

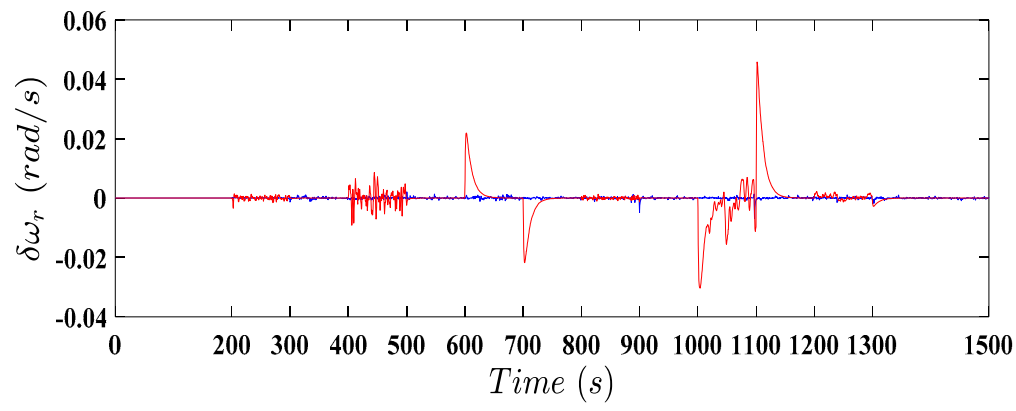

Figure 21. $\delta \omega_{\mathrm{r}}$ using the proposed controller (dark blue line) and PID controller (red line), with the first fault scenario.

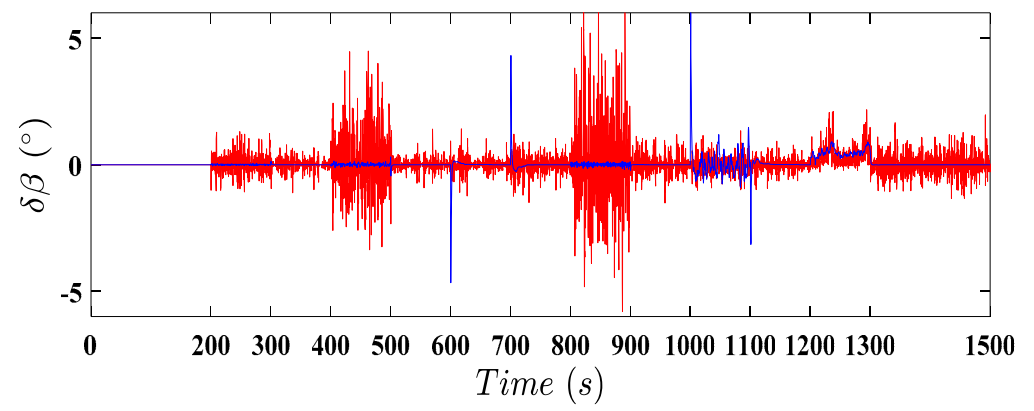

Figure 22. $\delta \beta$ using the proposed controller (dark blue line) and PID controller (red line), with the first fault scenario. 
Table 5. Performance metrics with the first fault scenario.

\begin{tabular}{cccc}
\hline Performance Metrics & Proposed Controller & PID Controller & Unit \\
\hline C1 & $\mathbf{1 5 5}$ & 2552 & $\mathrm{rad}^{2} / \mathrm{s}$ \\
C2 & $\mathbf{4 1 4 . 8}$ & 2506 & $\mathrm{GW}^{2} \mathrm{~s}$ \\
C3 & $\mathbf{0 . 0 5 6}$ & 0.2941 & $\mathrm{MW}$ \\
C4 & $\mathbf{0 . 0 0 1 3 4 9}$ & 0.001438 & $\mathrm{rad}^{2} / \mathrm{s}$ \\
C5 & $\mathbf{2 9 . 2 6}$ & 30 & $\circ$ \\
C6 & 10 & 10 & $\circ / \mathrm{s}$ \\
\hline
\end{tabular}

\subsection{Fault Identification Analysis}

In this section, with the aid of the estimated fault, $\hat{\mathrm{f}}$, and the calculated auxiliary signals of Equation (63), the fault identification performance is analyzed using the indices in Equation (64). The identification task includes fault detection, isolation, and its reconstruction (i.e., its shape). Consequently, the estimated pitch actuator bias, $\hat{\Phi}$, is obtained using Equation (65), in which $\mathrm{S}_{\beta_{u}}$ is calculated using $S_{\beta_{u}}=2 \eta(\bar{\rho}+\underline{\rho}) /\left.\left(P+P^{-1}\right)^{2}\right|_{\beta_{s}}$. It should be noted that the indices in Equation (64) and the estimated fault, $\hat{\mathrm{f}}$, should be computed and compared in every time step of simulation in order to accurately identify the fault. However, since the overall performance of the proposed fault identification technique is analyzed, the comparisons are performed in each fault period of Table 4. Also, as the calculated auxiliary signal for the fault-free case, i.e., $\mathrm{f}_{\text {auxiliary,fault free, is always }}$ zero, then the $\mathrm{VAF}_{\text {fault free }}$ in Equation (64) is calculated as $\operatorname{var}(\hat{\mathrm{f}}) \times 100 \%$. Now, to investigate the fault identification capability of the proposed controller, the estimated signal is shown in Figure 23. Also, the auxiliary signals computed from Equation (63) are depicted in Figure 24. Moreover, by means of the fault identification indices in Equation (64), summarized in Table 6, the estimated pitch actuator bias is shown in Figure 25. As remarked above, to fulfil the fault identification task, the values of the RMSE and the VAF indices closer to zero and $100 \%$, respectively, determine the fault case. Considering Table 6 , it is clear that in each fault-free period, the indices are indicating the fault-free case. Also, the estimated pitch actuator bias is zero. It is worth noting that in the fault-free periods, the VAF indices calculated for the dynamic change cases, are negative. Indeed, this result is justified considering the form of Equation (64). Comparing Figures 23 and 24, it can be pointed out that in the fault-free periods, $\operatorname{var}\left(\mathrm{f}_{\text {auxiliary },} \mathrm{x}-\hat{\mathrm{f}}\right)$ is greater than $\operatorname{var}\left(\mathrm{f}_{\text {auxiliary, }, \mathrm{X}}\right)$, which leads to negative VAF. Obviously, this is not the case considering the calculated VAF, using the fault-free auxiliary signal.

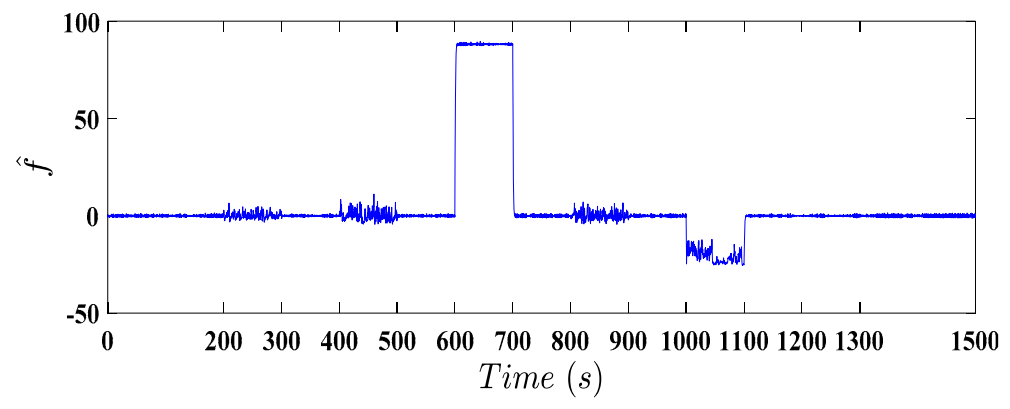

Figure 23. Estimated fault. 


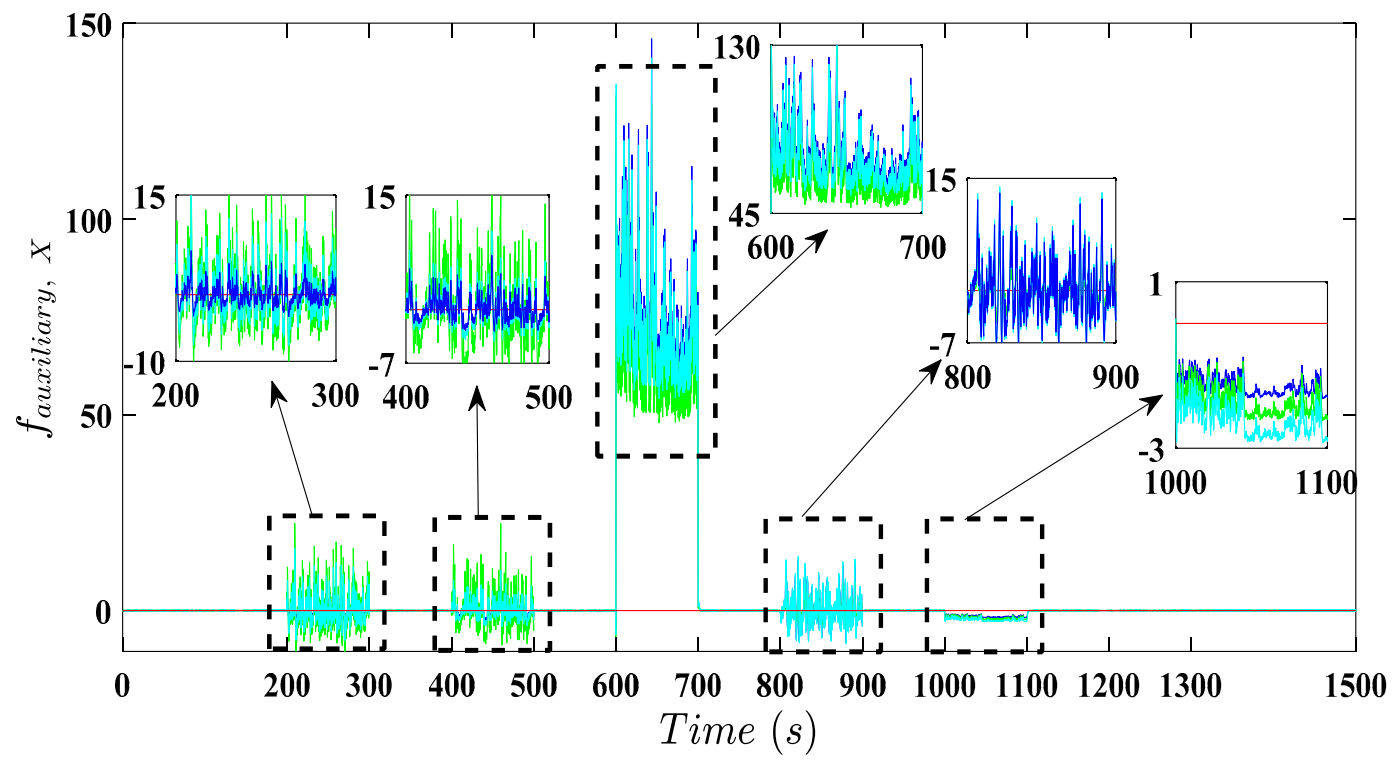

Figure 24. Auxiliary signal in the case of fault-free (red line), pump wear (dark blue line), high air content (green line), and hydraulic leak (light blue line).

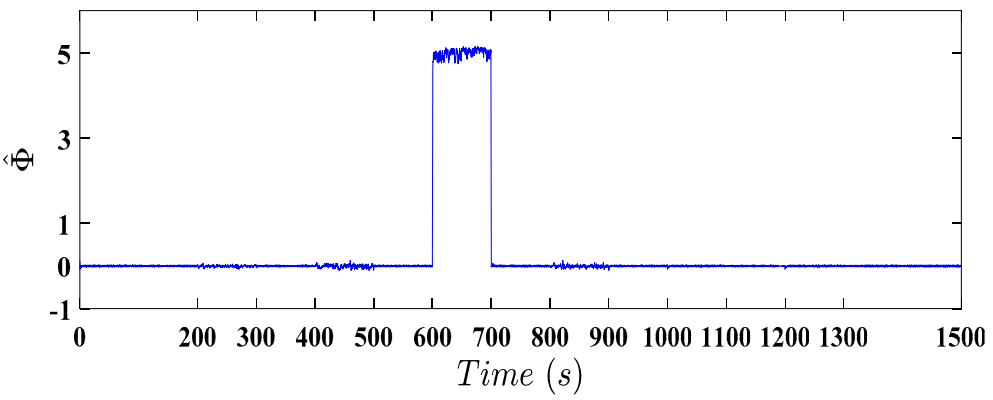

Figure 25. Estimated pitch actuator bias.

Table 6. Fault identification indices.

\begin{tabular}{|c|c|c|c|c|c|c|c|c|c|c|}
\hline \multirow{2}{*}{ Time (s) } & \multirow{2}{*}{ Fault Type } & \multicolumn{2}{|c|}{ High Air Content } & \multicolumn{2}{|c|}{ Hydraulic Leak } & \multicolumn{2}{|c|}{ Pump Wear } & \multicolumn{2}{|c|}{ Fault-Free } & \multirow{2}{*}{$\operatorname{Mean}(\hat{\Phi})$} \\
\hline & & RMSE & VAF & RMSE & VAF & RMSE & VAF & RMSE & VAF & \\
\hline 0-200 & Fault-Free & 0.37 & -788 & 0.36 & -842 & 0.39 & -5916 & 0.43 & 99.98 & 0 \\
\hline $200-300$ & Pump Wear & 3.25 & 50.94 & 1.94 & 66.65 & 0.15 & 98.91 & 1.46 & 215.1 & 0 \\
\hline $300-400$ & Fault-Free & 0.31 & -890 & 0.31 & -932 & 0.33 & -6291 & 0.37 & 97.65 & 0 \\
\hline $400-500$ & $\begin{array}{l}\text { Hydraulic } \\
\text { Leak }\end{array}$ & 2.40 & 75.01 & 0.19 & 99.26 & 67.99 & 2.4 & 2.54 & 575.7 & 0 \\
\hline $500-600$ & Fault-Free & 0.35 & -921 & 0.34 & -963 & 0.37 & -6420 & 0.41 & 99.86 & 0 \\
\hline $600-700$ & Pitch Bias & 27.82 & -41.85 & 21.99 & -32.33 & 18.67 & -24.33 & 87.62 & 4.05 & 5 \\
\hline $700-800$ & Fault-Free & 6.24 & -93370 & 6.20 & -68300 & 6.24 & -182000 & 6.35 & 97.85 & 0 \\
\hline $800-900$ & $\begin{array}{l}\text { High Air } \\
\text { Content }\end{array}$ & 0.42 & 97.50 & 1.81 & 76.41 & 1.64 & 79.01 & 1.95 & 383.5 & 0 \\
\hline 900-1000 & Fault-Free & 0.53 & -866 & 0.41 & -923 & 0.44 & -6309 & 0.05 & 99.89 & 0 \\
\hline $1000-1100$ & $\begin{array}{l}\text { Effectiveness } \\
\text { loss }\end{array}$ & 19.14 & -903 & 18.7 & -5800 & 19.56 & -16700 & 21.05 & 1100 & 0 \\
\hline 1100-1200 & Fault-Free & 1.71 & -8870 & 1.67 & -5990 & 1.75 & -17300 & 1.88 & 99.17 & 0 \\
\hline $1200-1300$ & $\begin{array}{l}\text { Aerodynamic } \\
\text { change }\end{array}$ & 0.29 & -751.6 & 0.28 & -807.9 & 0.31 & -5770 & 0.34 & 11.89 & 0 \\
\hline 1300-1500 & Fault-Free & 0.46 & -755 & 0.46 & -811 & 0.49 & -5790 & 0.54 & 98.38 & 0 \\
\hline
\end{tabular}

For the case of the pitch actuator dynamic changes, it can be verified that the selected indices lead to accurate identification of the corresponding actual dynamic change case. In all dynamic change cases, the estimated pitch actuator bias is zero. So, the dynamic change cases are clearly distinguishable 
from the pitch actuator bias. Evidently, during the pitch actuator bias period, none of the indices satisfying the considered conditions can be selected. On the other hand, the pitch actuator bias is precisely estimated. The situation is different for the cases of the pitch actuator effectiveness loss and the aerodynamic characteristic change. Obviously, neither the dynamic change case nor the fault-free case is selected, as the corresponding indices do not satisfy the given conditions. On the other hand, the pitch actuator bias is estimated as zero. Therefore, it can be concluded that these two periods correspond to the pitch actuator effectiveness loss and/or aerodynamic characteristic change. However, in order to correctly identify these two cases, the estimated fault is first considered, i.e., Figure 23. From Equation (41), it can be noted that the aerodynamic characteristic change is described as an additive disturbance while the effectiveness loss affects the control gain, i.e., $\mathrm{G}$ in Equation (41). The proposed controller has shown robustness features with respect to the considered disturbances. Accordingly, the estimated fault is affected by the effectiveness loss and it is insensitive to the aerodynamic characteristic change. Therefore, between 1000 and 1100 (s), as the estimated fault is different from zero, the effectiveness loss case is identified. Also, between 1200 and 1300 (s), as the estimated fault is zero, the aerodynamic characteristic change case is identified.

\subsection{Robustness Evaluation}

In this section, the proposed controller is further evaluated in terms of robustness to different wind speed sequences and fault scenarios. The wind speed is shown in Figure 26, with a mean of $20.41(\mathrm{~m} / \mathrm{s})$ and standard deviation of $3.01(\mathrm{~m} / \mathrm{s})$ for $1100(\mathrm{~s})$. Compared to the former wind speed reported in Figure 5, the signal considered in Figure 26 presents more fluctuations. So, it is more challenging for the controller to satisfy the objectives. Also, for the different fault scenario reported in Table 7, the faults occur simultaneously for a longer period. Also, the pitch actuator bias and the aerodynamic characteristic change values are increased. On the other hand, the pitch actuator effectiveness is decreased. For the sake of brevity, only the generated power in the fault-free and fault cases are considered for both the controllers. Considering these conditions, the performance metrics are compared. The generated power is illustrated in Figures 27 and 28, in both the fault-free and faulty situations, respectively. It is obvious that in both situations, the generated power is maintained within the prescribed constraints. The performance metrics are summarized in Tables 8 and 9, which further confirm that the proposed controller can successfully maintain reliable performance under faulty conditions. Its performances are clearly better than the ones achievable with the PID controller.

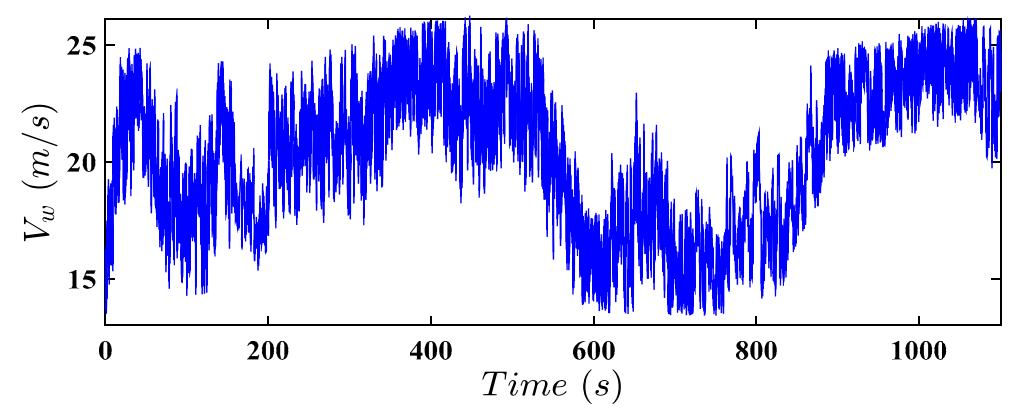

Figure 26. Second free wind speed profile.

Table 7. Second fault scenario.

\begin{tabular}{ccc}
\hline Fault Type & Fault Effect & Fault Period \\
\hline Pitch actuator pump wear & $\alpha_{\mathrm{f}_{1}}=0.6316, \alpha_{\mathrm{f}_{2}}=0.29688$ & $100(\mathrm{~s}) \leq \mathrm{t} \leq 300(\mathrm{~s})$ \\
Pitch actuator effectiveness loss & $\rho=0.5$ & $100(\mathrm{~s}) \leq \mathrm{t} \leq 300(\mathrm{~s})$ \\
Pitch actuator hydraulic leak & $\alpha_{\mathrm{f}_{1}}=1, \alpha_{\mathrm{f}_{2}}=0.87853$ & $400(\mathrm{~s}) \leq \mathrm{t} \leq 600(\mathrm{~s})$ \\
Pitch angle bias & $\Phi=10^{\circ}$ & $400(\mathrm{~s}) \leq \mathrm{t} \leq 600(\mathrm{~s})$ \\
Pitch actuator high air & $\alpha_{\mathrm{f}_{1}}=0.81083, \alpha_{\mathrm{f}_{2}}=1$ & $800(\mathrm{~s}) \leq \mathrm{t} \leq 1000(\mathrm{~s})$ \\
Aerodynamic characteristic change & $\Delta \mathrm{T}_{\mathrm{a}, \Delta \mathrm{C}_{\mathrm{p}}}=10 \%$ & $800(\mathrm{~s}) \leq \mathrm{t} \leq 1000(\mathrm{~s})$ \\
\hline
\end{tabular}




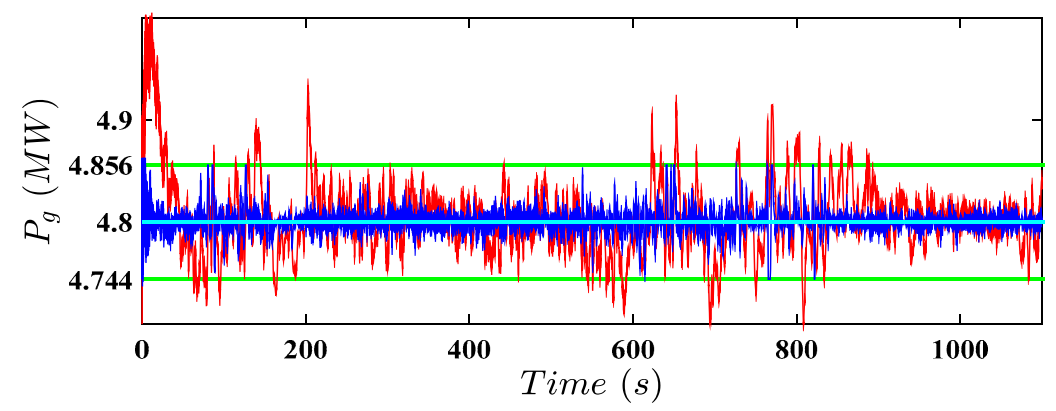

Figure 27. Generated power using the proposed controller (dark blue line), PID controller (red line), nominal power (light blue line), and constraints (green line), in the fault-free situation, with the second wind speed sequence.

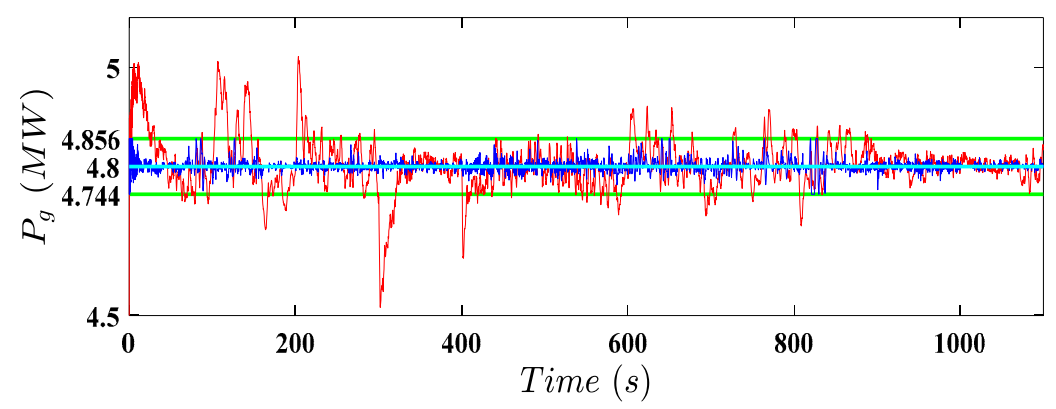

Figure 28. Generated power using the proposed controller (dark blue line), PID controller (red line), nominal power (light blue line), and constraints (green line), under the second fault scenario, with the second wind speed sequence.

Table 8. Performance metrics in the fault-free situation, with the second wind speed sequence.

\begin{tabular}{cccc}
\hline Performance Metrics & Proposed Controller & PID Controller & Unit \\
\hline C1 & $\mathbf{2 1 2 . 5}$ & 1762 & $\mathrm{rad}^{2} / \mathrm{s}$ \\
C2 & 465 & 1817 & $\mathrm{GW}^{2} \mathrm{~s}$ \\
C3 & $\mathbf{0 . 0 5 6}$ & 0.2094 & $\mathrm{MW}$ \\
C4 & $\mathbf{0 . 0 0 1 2 9 9}$ & 0.001371 & $\mathrm{rad}^{2} / \mathrm{s}$ \\
C5 & $\mathbf{2 9 . 1 2}$ & 30 & $\circ$ \\
C6 & 10 & $\mathbf{7 . 4 6}$ & $\circ / \mathrm{s}$ \\
\hline
\end{tabular}

Table 9. Performance metrics under the second fault scenario, with the second wind speed sequence.

\begin{tabular}{cccc}
\hline Performance Metrics & Proposed Controller & PID Controller & Unit \\
\hline C1 & $\mathbf{3 0 4 . 2}$ & 3747 & $\mathrm{rad}^{2} / \mathrm{s}$ \\
C2 & $\mathbf{5 4 4 . 9}$ & 3549 & $\mathrm{GW}^{2} \mathrm{~s}$ \\
C3 & $\mathbf{0 . 0 5 6}$ & 0.2214 & $\mathrm{MW}$ \\
C4 & 0.001421 & $\mathbf{0 . 0 0 1 3 7 6}$ & $\mathrm{rad}^{2} / \mathrm{s}$ \\
C5 & $\mathbf{2 9 . 4 0}$ & 30 & $\circ$ \\
C6 & 10 & 10 & $\circ / \mathrm{s}$ \\
\hline
\end{tabular}

Considering the simulation results in the fault-free and first fault scenario of Table 4 using the wind profile of Figure 5, it can be pointed out that the proposed controller is able to reduce the degradation of the wind turbine performances. Firstly, it is shown that the generated power never violates the given bound. It should be noted that this bound is appropriately selected by the wind turbine manufacturer. Indeed, this bound represents the safe-to-operate bound in full load operation without mechanical brake engagement. On the other hand, mechanical braking increases the induced fatigue load on the drive train. Also, the rotor acceleration is constrained, thus leading to reduce the torque stress on the 
rotor shaft. So, it can be concluded that the proposed controller leads to induce lower fatigue load and stress to the drive train. One obvious benefit of the proposed controller is that harsh long-lasting pitch actuator saturation is avoided. In fact, using the smooth pitch actuator saturation function, the speed of the pitch actuator response increases before the saturation, as highlighted in Figure 1. This characteristic leads to improved power regulation. It illustrates that the induced drive train torsion angle rate was kept at the same level as the baseline controller one. So, if the behavior of the baseline PID regulator is universally accepted in industrial control, the proposed controller can be used by industries to reduce the applied torsional stress. It is evident that the estimated aerodynamic torque fluctuates around the nominal one due to the inherent features of the RBF neural network and the Gaussian basis functions. However, as mentioned in the controller design procedure, the estimation error is bounded. This is obvious when comparing the actual aerodynamic torque and the estimated one. As remarked earlier, the pitch actuator dynamic change leads to a slower response of the pitch actuator and consequently poor power regulation. This phenomenon is highlighted in Figures 19 and 22. Nevertheless, the proposed controller was able to attenuate this effect, which is the same as the pitch actuator bias, using the properly designed fault estimator. On the other hand, the effects of the pitch actuator effectiveness loss and debris build-up are mitigated appropriately, satisfying the performance objectives. Also, using the fault estimator information alongside the proposed fault identification scheme, different faults are identified. Similar results can be obtained for even more severe instantaneous faults and higher wind speed variation, as illustrated in Figures 27 and 28.

\section{Conclusions and Open Problems}

This paper proposed a novel adaptive constrained control methodology for wind turbine power regulation subject to actuation failures as well as unknown system dynamics. In contrast to previous works where an unknown wind speed observer/estimator was needed, using the Nussbaum-type function, the proposed method was able to handle the unpredictable wind speed variation effects in the control design without requiring accurate wind speed measurement. The constrained rotor speed and generated power were guaranteed while the pitch actuator remained within the desired bounds. Using the barrier Lyapunov function in conjunction with the concept of dynamic surface control, a constrained stable control structure with cheap computational cost was developed. In addition, utilizing a radial basis functions neural network together with a proper fault-tolerant scheme, a robust and adaptive scheme was developed without the need for precise information about either the wind turbine model or the pitch actuator faults. Numerical simulations were finally performed to validate the effectiveness of the reported theoretical developments, and comparisons with the available industrial controller performance were shown.

Finally, by considering the proposed controller in this paper and the investigated results, the future research direction of this paper can be outlined as the validation of the proposed controller by means of data acquired from real or experimental-scale wind turbines for the whole operational region, achieving the Industry 4.0 requirements.

Author Contributions: Conceptualization, H.H. and H.R.N.; methodology, H.H. and H.R.N.; software, H.H.; validation, H.H., S.S. and I.H.; formal analysis, H.H., I.H. and S.S.; investigation H.H. and S.S.; writing-original draft preparation, H.H.; writing-review and editing, H.H., H.R.N., I.H. and S.S.; visualization, H.H.; supervision, I.H. and S.S.

Funding: This research received no external funding.

Conflicts of Interest: The authors declare no conflict of interest. 


\section{Nomenclature}

$\mathbf{B}_{\mathrm{dt}} \quad$ Drive train torsion damping

$\mathrm{B}_{\mathrm{g}} \quad$ Generator viscous friction

$\mathrm{B}_{\mathrm{r}} \quad$ Rotor viscous friction

$\mathrm{B}_{\mathrm{t}} \quad$ Tower damping ratio

$\mathrm{C}_{\mathrm{p}} \quad$ Power coefficient

$\mathrm{C}_{\mathrm{q}} \quad$ Torque coefficient

$\mathrm{C}_{\mathrm{t}} \quad$ Thrust coefficient

$\mathrm{C} 1, \ldots, \mathrm{C} 6$ Performance metrics

$\Delta \mathrm{C}_{\mathrm{p}} \quad$ Power coefficient change

$\overline{\mathrm{D}}, \overline{\mathrm{D}}_{1} \quad$ Unknown positive constants

$\mathrm{F}_{\mathrm{t}} \quad$ Aerodynamic thrust

$\mathrm{f}_{\text {auxiliary, }} \mathrm{X}$ Auxiliary signal for fault case $X$

$\bar{f} \quad$ Unknown positive constant

$\mathrm{H} \quad$ Pitch actuator saturation

$\mathrm{h}_{\mathrm{i}} \quad$ Gaussian function

$\mathrm{Jg}_{\mathrm{g}} \quad$ Generator inertia

$\mathrm{J}_{\mathrm{r}} \quad$ Rotor inertia

$\mathrm{K}_{\mathrm{dt}} \quad$ Drive train torsion stiffness

$\mathrm{K}_{\mathrm{D}} \quad$ Derivative gain

$\mathrm{K}_{\mathrm{I}} \quad$ Integral gain

$\mathrm{K}_{\mathrm{P}} \quad$ Proportional gain

$\mathrm{K}_{\mathrm{t}} \quad$ Tower elasticity coefficient

$\mathrm{k}_{\mathrm{e}_{\mathrm{i}}} \quad$ Constraint on $\mathrm{e}_{\mathrm{i}}$

$\overline{\mathrm{k}}_{1} \quad$ Unknown positive constant

$\mathrm{M}_{\mathrm{t}} \quad$ Nacelle mass

N Nussbaum-type function

$\mathrm{P}_{\mathrm{g}} \quad$ Generated electrical power

$\mathrm{R} \quad$ Blade length

S Saturation smooth estimation

s Number of nodes

$\mathrm{T}_{\mathrm{a}} \quad$ Aerodynamic torque

$\mathrm{T}_{\mathrm{a}, \mathrm{NN}} \quad$ Approximation of $\mathrm{T}_{\mathrm{a}}$

$\mathrm{T}_{\mathrm{g}} \quad$ Generator torque

$\mathrm{V}_{\mathrm{r}} \quad$ Effective wind speed

$\mathrm{V}_{\mathrm{w}} \quad$ Free wind speed

$V_{1}, V_{2} \quad$ Lyapunov functions

$\mathbf{X}_{\mathbf{N}} \quad$ Nominal value of $\mathbf{X}$

$X_{S} \quad$ Measurement of $X$

$\widetilde{X} \quad$ Estimation error of $X$

$\hat{X} \quad$ Estimation of $X$

$x_{t} \quad$ Nacelle displacement

$\alpha_{\mathrm{f}_{1}}, \alpha_{\mathrm{f}_{2}} \quad$ Fault indicators

$\alpha_{1} \quad$ Virtual control

$\beta \quad$ Pitch angle

$\beta_{\text {ref }} \quad$ Reference pitch angle

$\beta_{\mathrm{u}} \quad$ Pitch actuator effort

$\Gamma \quad$ Design matrix

$\gamma_{1}, \gamma_{2} \quad$ Positive design parameters

$\varepsilon \quad$ Approximation error

$\bar{\varepsilon} \quad$ Unknown positive constant

$\eta \quad$ Positive design parameter

$\eta_{\mathrm{g}} \quad$ Generator efficiency

$\eta_{1}, \eta_{2}, \eta_{3}, \eta_{4}$ Positive design parameters 


$\begin{array}{ll}\theta_{\mathrm{g}} & \text { Generator rotation angle } \\ \theta_{\mathrm{r}} & \text { Rotor rotation angle } \\ \theta_{\Delta} & \text { Drive train twist angle } \\ \theta^{*} & \text { Optimal weight vector } \\ \vartheta_{\mathrm{i}} & \mathrm{i}^{\text {th }} \text { centre vector of the inputs } \\ \lambda & \text { Tip speed ratio } \\ v_{\mathrm{X}} & \text { Noise content of variable } \mathrm{X} \\ \xi & \text { Pitch actuator damping ratio } \\ \xi_{\mathrm{X}} & \text { Damping ratio in the situation } \mathrm{X} \\ \rho & \text { Unknown actuator effectiveness } \\ \rho_{\mathrm{a}} & \text { Air density } \\ \rho_{\mathrm{f}}, \rho_{\overline{\mathrm{f}}} & \text { Unknown positive constants } \\ \sigma_{\mathrm{f}}, \sigma_{\mathrm{c}}, \sigma_{\mathrm{d}} & \text { Positive design parameters } \\ \tau_{2} & \text { Time constant } \\ \Phi & \text { Unknown pitch actuator bias } \\ \varphi_{\mathrm{c}} & \text { Gaussian functions width vector } \\ \omega_{\mathrm{g}} & \text { Generator speed } \\ \omega_{\mathrm{n}} & \text { Pitch actuator natural frequency } \\ \omega_{\mathrm{n}, \mathrm{X}} & \text { Natural frequency in situation X } \\ \omega_{\mathrm{r}} & \text { Rotor speed }\end{array}$

\section{References}

1. You, G.; Xu, T.; Su, H.; Hou, X.; Wang, X.; Fang, C.; Li, J. Fault-tolerant control of doubly-fed wind turbine generation systems under sensor fault conditions. Energies 2019, 12, 3239. [CrossRef]

2. Habibi, H.; Howard, I.; Simani, S. Reliability improvement of wind turbine power generation using model-based fault detection and fault tolerant control: A review. Renew. Energy 2019, 135, 877-896. [CrossRef]

3. Simani, S.; Castaldi, P.; Farsoni, S. Data-driven fault diagnosis of a wind farm benchmark model. Energies 2017, 10, 866. [CrossRef]

4. Lan, J.; Patton, R.J.; Zhu, X. Fault-tolerant wind turbine pitch control using adaptive sliding mode estimation. Renew. Energy 2018, 116, 219-231. [CrossRef]

5. Habibi, H.; Nohooji, H.R.; Howard, I. Constrained control of wind turbines for power regulation in full load operation. In Proceedings of the 11th Asian Control Conference (ASCC), Gold Coast, Australia, 17-20 December 2017; pp. 2813-2818.

6. Boukhezzar, B.; Siguerdidjane, H. Nonlinear control of a variable-speed wind turbine using a two-mass model. IEEE Trans. Energy Convers. 2011, 26, 149-162. [CrossRef]

7. Sloth, C.; Esbensen, T.; Stoustrup, J. Robust and fault-tolerant linear parameter-varying control of wind turbines. Mechatronics 2011, 21, 645-659. [CrossRef]

8. Bianchi, F.D.; De Battista, H.; Mantz, R.J. Wind Turbine Control Systems: Principles, Modelling and Gain Scheduling Design; Springer Science \& Business Media: London, UK, 2006.

9. Jafarnejadsani, H.; Pieper, J.; Ehlers, J. Adaptive control of a variable-speed variable-pitch wind turbine using radial-basis function neural network. IEEE Trans. Control Syst. Technol. 2013, 21, 2264-2272. [CrossRef]

10. Giger, U.; Kühne, P.; Schulte, H. Fault tolerant and optimal control of wind turbines with distributed high-speed generators. Energies 2017, 10, 149. [CrossRef]

11. Jaramillo-Lopez, F.; Kenne, G.; Lamnabhi-Lagarrigue, F. A novel online training neural network-based algorithm for wind speed estimation and adaptive control of pmsg wind turbine system for maximum power extraction. Renew. Energy 2016, 86, 38-48. [CrossRef]

12. Kim, Y.-M. Robust data driven h-infinity control for wind turbine. J. Frankl. Inst. 2016, 353, $3104-3117$. [CrossRef]

13. Badihi, H.; Zhang, Y.; Hong, H. Wind turbine fault diagnosis and fault-tolerant torque load control against actuator faults. IEEE Trans. Control Syst. Technol. 2015, 23, 1351-1372. [CrossRef]

14. Tiwari, R.; Babu, N.R. Recent developments of control strategies for wind energy conversion system. Renew. Sustain. Energy Rev. 2016, 66, 268-285. [CrossRef] 
15. Odgaard, P.F.; Stoustrup, J. A benchmark evaluation of fault tolerant wind turbine control concepts. IEEE Trans. Control Syst. Technol. 2015, 23, 1221-1228. [CrossRef]

16. Song, Y.; Huang, X.; Wen, C. Robust adaptive fault-tolerant pid control of mimo nonlinear systems with unknown control direction. IEEE Trans. Ind. Electron. 2017, 64, 4876-4884. [CrossRef]

17. Habibi, H.; Howard, I.; Habibi, R. Bayesian fault probability estimation: Application in wind turbine drivetrain sensor fault detection. Asian J. Control 2018. [CrossRef]

18. Simani, S. Overview of modelling and advanced control strategies for wind turbine systems. Energies 2015, 8, 13395-13418. [CrossRef]

19. Simani, S.; Farsoni, S.; Castaldi, P. Fault diagnosis of a wind turbine benchmark via identified fuzzy models. IEEE Trans. Ind. Electron. 2015, 62, 3775-3782. [CrossRef]

20. Tabatabaeipour, S.M.; Odgaard, P.F.; Bak, T.; Stoustrup, J. Fault detection of wind turbines with uncertain parameters: A set-membership approach. Energies 2012, 5, 2424-2448. [CrossRef]

21. Habibi, H.; Nohooji, H.R.; Howard, I. Optimum efficiency control of a wind turbine with unknown desired trajectory and actuator faults. J. Renew. Sustain. Energy 2017, 9, 063305. [CrossRef]

22. Song, D.; Yang, J.; Cai, Z.; Dong, M.; Su, M.; Wang, Y. Wind estimation with a non-standard extended kalman filter and its application on maximum power extraction for variable speed wind turbines. Appl. Energy 2017, 190, 670-685. [CrossRef]

23. Petković, D.; Arif, M.; Shamshirband, S.; Bani-Hani, E.H.; Kiakojoori, D. Sensorless estimation of wind speed by soft computing methodologies: A comparative study. Informatica 2015, 26, 493-508. [CrossRef]

24. Jena, D.; Rajendran, S. A review of estimation of effective wind speed based control of wind turbines. Renew. Sustain. Energy Rev. 2015, 43, 1046-1062. [CrossRef]

25. Habibi, H.; Nohooji, H.R.; Howard, I. Backstepping nussbaum gain dynamic surface control for a class of input and state constrained systems with actuator faults. Inf. Sci. 2019, 482, 27-46. [CrossRef]

26. Habibi, H.; Nohooji, H.R.; Howard, I. Adaptive pid control of wind turbines for power regulation with unknown control direction and actuator faults. IEEE Access 2018, 6, 37464-37479. [CrossRef]

27. Georg, S.; Schulte, H.; Aschemann, H. Control-oriented modelling of wind turbines using a takagi-sugeno model structure. In Proceedings of the IEEE International Conference on Fuzzy Systems (FUZZ-IEEE), Brisbane, Australia, 13 August 2012; pp. 1-8.

28. Zhao, K.; Song, Y.; Wen, C. Computationally inexpensive fault tolerant control of uncertain non-linear systems with non-smooth asymmetric input saturation and undetectable actuation failures. IET Control Theory Appl. 2016, 10, 1866-1873. [CrossRef]

29. Badihi, H.; Zhang, Y.; Hong, H. Fuzzy gain-scheduled active fault-tolerant control of a wind turbine. J. Frankl. Inst. 2014, 351, 3677-3706. [CrossRef]

30. Shanzhi, L.; Haoping, W.; Yang, T.; AITOUCHE, A. A rbf neural network based mppt method for variable speed wind turbine system. IFAC-PapersOnLine 2015, 48, 244-250.

31. Rahimi, H.N.; Howard, I.; Cui, L. Neural impedance adaption for assistive human-robot interaction. Neurocomputing 2018, 290, 50-59. [CrossRef]

32. Ge, S.S.; Hang, C.C.; Lee, T.H.; Zhang, T. Stable Adaptive Neural Network Control; Springer Science \& Business Media: New York, NY, USA, 2013.

33. Ge, S.S.; Hong, F.; Lee, T.H. Adaptive neural control of nonlinear time-delay systems with unknown virtual control coefficients. IEEE Trans. Syst. Man Cybern. 2004, 34, 499-516. [CrossRef]

34. Rahimi, H.N.; Howard, I.; Cui, L. Neural adaptive tracking control for an uncertain robot manipulator with time-varying joint space constraints. Mech. Syst. Signal Proc. 2018, 112, 44-60. [CrossRef]

(C) 2019 by the authors. Licensee MDPI, Basel, Switzerland. This article is an open access article distributed under the terms and conditions of the Creative Commons Attribution (CC BY) license (http://creativecommons.org/licenses/by/4.0/). 